\title{
Resolving the Ophioderma longicauda (Echinodermata: Ophiuroidea) cryptic species complex: five sisters, three of them new
}

\author{
Sabine STÖHR ${ }^{1, *}$, Alexandra Anh-Thu WEBER ${ }^{2}$, Emilie BOISSIN $^{3} \&$ Anne CHENUIL $^{4}$ \\ ${ }^{1}$ Swedish Museum of Natural History, Department of Zoology, \\ Frescativägen 40, S-10405 Stockholm, Sweden. \\ ${ }^{2}$ Marine invertebrates, Museum Victoria, GPO Box 666, Melbourne VIC 3001, Australia. \\ ${ }^{2}$ IFREMER, Centre de Bretagne, REM/EEP, Laboratoire Environnement Profond, \\ 29280 Plouzané, France. \\ ${ }^{3}$ PSL Research University: EPHE-UPVD-CNRS, USR3278 CRIOBE, \\ Université de Perpignan, 52 Avenue Paul Alduy, 66860 Perpignan Cedex, France. \\ ${ }^{4}$ Aix-Marseille Université, Institut Méditerranéen de Biodiversité et d'Ecologie marine et continentale \\ (IMBE) - CNRS - IRD - UAPV, Station Marine d'Endoume, \\ Chemin de la Batterie des Lions, F-13007 Marseille, France. \\ *Corresponding author: sabine.stohr@nrm.se \\ ${ }^{2}$ Email: aweber@museum.vic.gov.au \\ ${ }^{3}$ Email: emilie.boissin@univ-perp.fr \\ ${ }^{4}$ Email: anne.chenuil@imbe.fr \\ ${ }^{1}$ urn:1sid:zoobank.org:author:412800EB-AACE-4313-9810-61F89B740405 \\ ${ }^{2}$ urn:1sid:zoobank.org:author:0C152E34-0CD1-4F4F-81AE-818AC5018F1C \\ ${ }^{3}$ urn:1sid:zoobank.org:author:B35FF544-AE44-43B2-B1CA-3769A281F386 \\ ${ }^{4}$ urn:1sid:zoobank.org:author:8B07D296-065B-44D4-B4B1-D744B9D9546A
}

\begin{abstract}
The conspicuous Mediterranean brittle star Ophioderma longicauda (Bruzelius, 1805) has been discovered to represent a cryptic species complex, consisting of six nuclear clusters with contrasting reproductive modes (broadcast spawners and brooders). Here, O. longicauda is re-described. It is distinguished by a dark reddish-brown colouration both dorsally and on the ventral disc, and multiple tumid dorsal arm plates. One eastern Mediterranean brooding cluster is described as $O$. zibrowii sp. nov., characterized by a dark olive-green colour both dorsally and on the ventral disc, and single dorsal arm plates. Another brooder is described from Tunisia as $O$. hybrida sp. nov., with a highly variable morphology that reflects its origin by hybridization of $O$. longicauda and a brooder (possibly O. zibrowii sp. nov.), leaving the third brooding cluster as morphologically indistinguishable at this point and possibly conspecific with one of the others. The West-African $O$. guineense Greef, 1882 is resurrected as a valid species, differing morphologically from $O$. longicauda by predominantly single dorsal arm plates and light green or creamy white ventral side. Also from West Africa, O. africana sp. nov. is described, characterized by a dark brown colour, dorsally and ventrally, and single dorsal arm plates.
\end{abstract}

Keywords. Brittle stars, new species, morphology, Mediterranean Sea, West Africa. 
Stöhr S., Weber A.A.-T., Boissin E. \& Chenuil A. 2020. Resolving the Ophioderma longicauda (Echinodermata: Ophiuroidea) cryptic species complex: five sisters, three of them new. European Journal of Taxonomy 600: 1-37. https://doi.org/10.5852/ejt.2020.600

\section{Introduction}

Ophioderma longicauda (Bruzelius, 1805) is a large and conspicuous species of brittle star, reported from the coast of the Mediterranean Sea and in the East Atlantic Ocean from Portugal to West Africa (Stöhr et al. 2009). It has also been collected at Madeira and the Canary Islands (Boissin et al. 2011). For a long time, $O$. longicauda was assumed to be a single species across its entire geographic range, described as morphologically highly variable (Tortonese 1983). Its reproductive mode was reported to be broadcast spawning with a vitellaria larva, occurring in the summer months of July and August (Fenaux 1969, 1972). About a decade ago, it was discovered that there are individuals in the easternMediterranean populations of Ophioderma Müller \& Troschel, 1840, morphologically extremely similar to O. longicauda, but reproducing by brooding eggs and young (Stöhr et al. 2009). It was at first unclear if this was a rare case of poecilogony or evidence of a cryptic species complex. Further studies discovered six mitochondrial (COI) lineages (named L1-L6), three of them brooding and three broadcast spawning (Boissin et al. 2011) (Fig. 1A). All brooders are restricted to the eastern Mediterranean, but spawners occur across the whole Mediterranean Sea and are found in sympatry with brooders in the east (Fig. 1BC). The most common lineages were L1 (spawners) and L3 (brooders, from Greece), and these were subjected to further studies. The absence of gene flow and contrasting genetic structures between these lineages of brooders and spawners suggested that they comprise at least two different biological species (Boissin et al. 2011; Weber et al. 2014, 2015). Further investigation provided strong evidence for the existence of up to six species, corresponding to six genetic clusters (C1-C6; Fig. 1A) (Weber et al. 2019). Consequently, two broadcast spawning species are found off West Africa, two brooders are only found in the eastern Mediterranean Sea and may form a single species or two, one species ranges from the Canary Islands across the entire Mediterranean Sea and was identified as O. longicauda s. str., and one brooding species seems to be restricted to Tunisia (Fig. 1). This means that at least three species are taxonomically undescribed and unnamed.

Preferably, the formal description of a new species should be based on morphological characters, not on genetic data alone. Ophioderma longicauda was described more than two centuries ago (Bruzelius 1805), but it was only recently recognized as a complex of cryptic species because their morphological differences were interpreted as intraspecific variability, which demonstrates the difficulties in finding diagnostic characters to differentiate the newly found genetic clusters. Reproduction mode may serve as a biological trait that separates three brooding clusters $(\mathrm{C} 4, \mathrm{C} 5$, and $\mathrm{C} 6)$ from the remaining broadcast spawning clusters (C1-C3) (Fig. 1A) (Weber et al. 2019). However, since all putative species in the O. longicauda complex are gonochoric, and brooding is limited to the period May-June, only mature brooding females are identifiable beyond doubt and only during a brief period of time. Identification of males, juveniles, and females outside the brooding season has so far had to rely on characters with limited taxonomic value. For instance, morphometric examinations suggested that spawners reach a larger size than brooders (Stöhr et al. 2009; Weber et al. 2014), which is a character with limited taxonomic value since only individuals above a certain size can be confidently identified. The state of the radial shields as naked or covered with granules has been examined closer because this character is diagnostic for other species of Ophioderma (Ziesenhenne 1955), and the results suggest a tendency towards naked radial shields in brooders from Crete and granule covered radial shields in spawners (Stöhr et al. 2009; Weber et al. 2014), but some variability is present. Already Tortonese (1983) had recorded both naked and covered radial shields, and noted that naked ones were found mainly in southern populations (from Israel and Cyprus), which suggests that he may unknowingly have had specimens of the brooding lineages among his samples. Brooders and spawners differ in reproduction time (early May in brooders, July in 


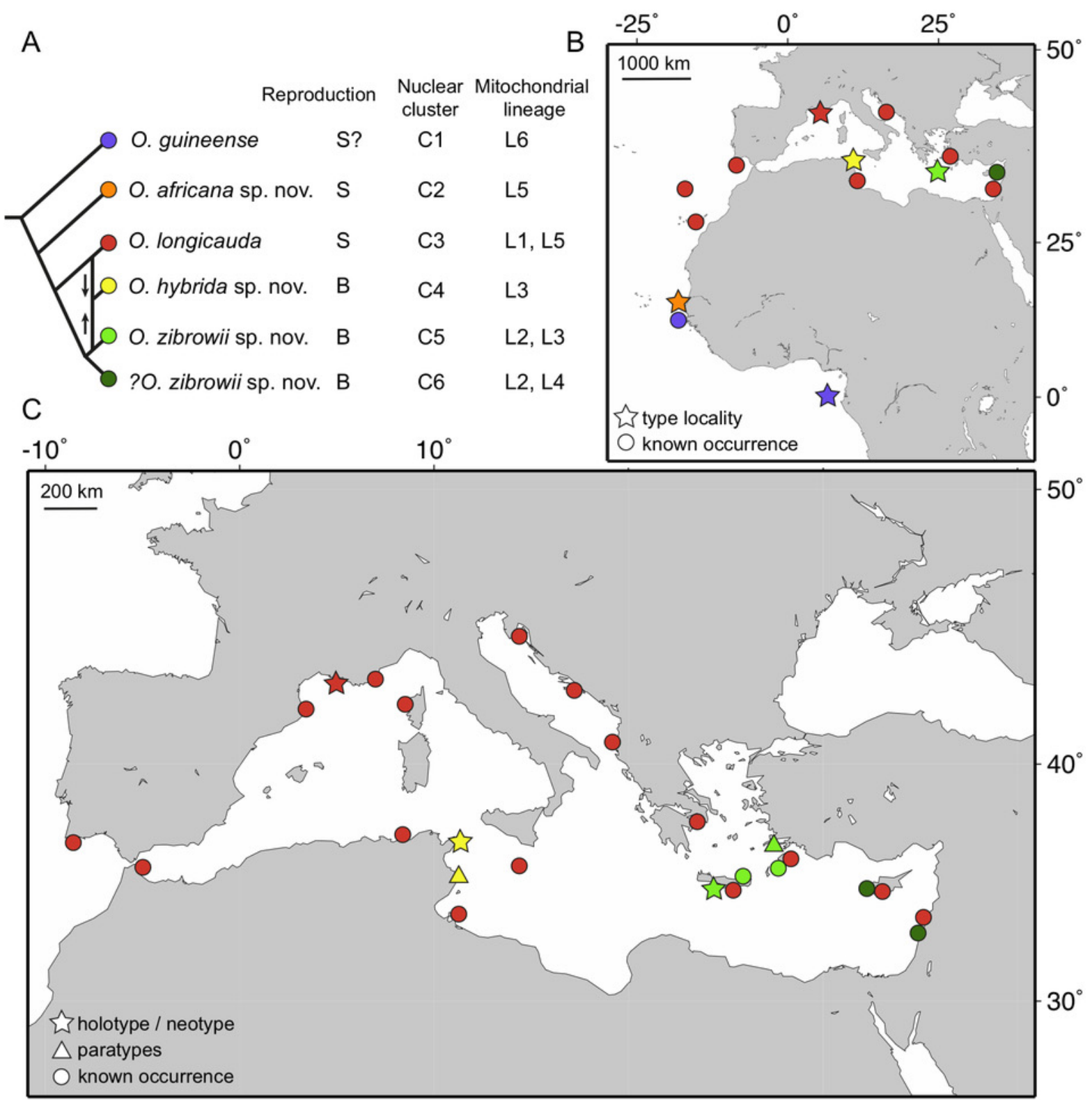

Fig. 1. Phylogenetic relationships and distribution of species of Ophioderma Müller \& Troschel, 1840 in the Northeast and Tropical Atlantic Ocean and the Mediterranean Sea. A. Simplified phylogenetic relationships among species of Ophioderma described in this study, modified from Weber et al. (2019). Summary of reproductive strategy: $\mathrm{S}=$ broadcast spawner; $\mathrm{B}=$ brooder. Correspondence between species names, nuclear genetic clusters and COI mitochondrial lineages is summarized from Boissin et al. (2011) and Weber et al. (2019). C6 is tentatively assigned to O. zibrowii sp. nov. because it occurs far from the type locality and brooding species are expected to have low dispersal rates, leading to low gene flow between populations. B. Distribution of species of Ophioderma in the Northeast and Tropical Atlantic Ocean. C. Distribution of species of Ophioderma in the Mediterranean Sea. 
spawners), which was confirmed for sympatric populations (Weber et al. 2014). Considering ecological requirements to separate species, we found experimentally that brooding individuals of mitochondrial lineage $\mathrm{L} 3$ (= C5) appear to be adapted to warmer waters (displayed better survival at $26^{\circ} \mathrm{C}$ and $30^{\circ} \mathrm{C}$ ) compared to broadcasting individuals of lineage L1 (=C3) (Weber et al. 2013). Furthermore, L3 appears to be more common at depths of $1-3 \mathrm{~m}$, whereas L1 is found in greater numbers at greater depths $(>10$ m) (Weber et al. 2014); there is however considerable overlap in depth range. In the present study, colour pattern was discovered as having high taxonomic value in these species.

Mitochondrial lineages and nuclear genetic clusters do not exactly correspond on a one-to-one basis (Fig. 1A). Although there is no doubt that the clusters defined from numerous nuclear markers are the grounds on which the species should be delimited (Weber et al. 2019) rather than lineages from a single mitochondrial marker, we give the comparisons here because mitochondrial data were published first (Boissin et al. 2011) and also because a single mitochondrial marker is only available in many other cryptic species complexes in the literature (Boissin et al. 2017; Chenuil et al. 2019). For instance, the cluster $\mathrm{C} 3$ (spawners) includes all individuals of the mitochondrial lineage L1 and some from L5, and has the widest distribution, occurring across the whole Mediterranean Sea and in the East Atlantic (Fig. 1). It is the most common genetic entity, supported by large amounts of data. Among the brooders, C5 is the best-supported cluster with data from a large number of individuals, and includes all individuals of L3 and part of L2 (only those from Greece, excluding those from Lebanon). Despite the difficulties with finding unambiguous morphological differences, we propose to differentiate two species, based on clusters $\mathrm{C} 3(O$. longicauda) and $\mathrm{C} 5$ (O. zibrowii sp. nov.). Among the remaining clusters, $\mathrm{C} 1$, which is found in West Africa, differs clearly from O. longicauda, which prompted us to compare the specimens with Ophioderma guineense Greef, 1882, a species that was until now considered conspecific with O. longicauda (Madsen 1970). We found it to be morphologically different and propose to treat $O$. guineense as a valid species. Likewise, cluster $\mathrm{C} 2$ of broadcast spawners from Senegal was found to be morphologically distinct from all other clusters and is described as another new species $(O$. africana sp. nov.) in this study. In addition, cluster $\mathrm{C} 4$ from Tunisia (a brooder, based on older museum specimens) is also proposed as a new species (O. hybrida sp. nov.).

Finally, although there is significant genetic structure (as measured by $\mathrm{F}_{\mathrm{ST}}$, an index of genetic differentiation) between the two allopatric clusters of brooders C5 and C6 in the eastern Mediterranean Sea (Weber et al. 2019), the presence of genetic clustering (and therefore genetic structure) does not necessarily mean that there are different species. These are possibly two populations of the same species that have very low dispersal rates, and thus are not often connected. To avoid over splitting, we keep a conservative approach and describe a single brooding species in the eastern Mediterranean until more data are available (e.g., additional brooding populations from a denser geographic sampling; breeding experiments between $\mathrm{C} 5$ and $\mathrm{C} 6$ ).

The taxonomic status of $O$. longicauda was unclear for a long time because its discovery dates back to preLinnean times and naming conventions were still developing, as more and more species were discovered and assigned to new genera and families. It had been confused with Ophiura ophiura Linnaeus, 1758, and various names had been applied to both species, but it was always considered a Mediterranean species (Clark 1976). The nomenclatural problem was resolved by decision of the International Commission of Zoological Nomenclature (Melville 1980), which also decided that Ophioderma is of feminine gender. To stabilize a species concept, and to allow delimitation between different species, type material is required. Indeed, since $O$. longicauda is also the type species of its genus and family, a stable concept of this species is of great importance. The holotype of $O$. longicauda could not be located and must be assumed lost. Unfortunately, no lecto- or neotype has ever been designated because it was assumed that the identity of $O$. longicauda was beyond doubt (Clark 1976). However, with the discovery of several sister species, the concept of $O$. longicauda was no longer clear. For more than 200 years, the concept of 
the species has been that of a large broadcast spawner (Fenaux 1969, 1972; Tortonese 1983), and older studies were conducted mainly on western Mediterranean populations (France, Italy), which suggests that the species concept most likely concurs best with cluster C3. Clusters $\mathrm{C} 1$ and $\mathrm{C} 2$ must be excluded because they are found only off West Africa. Ophioderma longicauda is therefore re-described based on a neotype selected from cluster C3/lineage L1 from the northwestern Mediterranean Sea (Marseille, France).

\section{Material and methods}

Type material of $O$. longicauda or any material from Bruzelius (1805) and Retzius (to whom O. longicauda was attributed for a long time) was searched for in the Zoological Museum in Lund, their home town, but nothing was found. Likewise, searches of the collections at the Swedish Museum of Natural History in Stockholm and the Museum of Evolution in Uppsala were unsuccessful. A single specimen of $O$. longicauda was selected from the western population of mitochondrial lineage L1. Although this particular individual has not been used in the larger study using multiple nuclear markers (designed to differentiate sympatric species, which occur only in the eastern Mediterranean), it can safely be assumed that all specimens of L1 are members of cluster C3 because the genetic analysis of numerous samples from various western Mediterranean locations showed that all belong to a single mitochondrial lineage and a single nuclear cluster, thereby assuring the least amount of ambiguity in the delimitation of the species. For internal skeletal characters, other specimens from L1 were selected for dissection, to avoid damage of the neotype.

For the brooding new species described below as $O$. zibrowii sp. nov., type material of cluster $\mathrm{C} 5$ was chosen from Crete and Symi Island, Greece, because these specimens were part of the study that discovered the clusters (Weber et al. 2019). Additional material from Crete and Rhodes belonging to lineage L3 has been assigned to the same species because all analysed specimens from Greece of this lineage fall within cluster $\mathrm{C} 5$. They are not included in the paratype series though, since brooding populations have low dispersal abilities and may diverge on a small geographic scale. Also, specimens of lineage L3 from Tunisia form a separate cluster, C4, which we propose to treat as another new species. Therefore, to avoid future complications, only specimens from the type locality or close-by sites are included in the type series of each species. Specimens belonging to C6 were not included in the type series of $O$. zibrowii sp. nov. because it is at present unclear whether they should be regarded as a separate species or not.

Three of seven syntypes of $O$. guineense were sent on loan by Zoological Museum, Hamburg; the remaining four were examined from photographs. A small arm piece was cut from each of the three borrowed syntypes of $O$. guineense and used to attempt DNA extraction, COI amplification and sequencing. This was however unsuccessful, most likely due to the old age ( $>136$ years) of the specimens. It is unknown whether they may have been preserved in formalin at some point, which would complicate access to DNA for correct amplification.

Specimens were photographed using a DSLR camera on a stepwise moving sled, taking stacks of images. Images were composed with the stacking software Zerene Stacker (Zerenesystems.com). Some photographs were taken with an Olympus TG4 compact camera and its automatic stacking feature. For the analysis of the internal skeleton, specimens of 15-16 mm disc diameter (dd) were selected because this was the most readily available size in all species. The skeleton changes during growth and comparisons should be made on individuals of similar size, assuming size corresponds to developmental stage or age. Ossicles were prepared by dissolving all soft tissue in concentrated household bleach $(\mathrm{NaOCl})$ and washing with tap water. The dissociated ossicles were then mounted (either wet in a drop of water or air dried) with spray glue on aluminium stubs for scanning electron microscopy, dried, examined and photographed with a Hitachi FE-S4300 and a FEI Quanta 650, respectively. Three 
specimens of $O$. hybrida sp. nov. had previously been used to examine the gonads for signs of brooding, by cutting off the dorsal disc and thus destroying the radial shields. Among the remaining specimens, most are smaller or larger than the size chosen $(15-16 \mathrm{~mm} \mathrm{dd})$ for ossicle examinations. We decided not to sacrifice specimens for the study of internal skeletal elements because this species shows a higher morphological variability than the other species, which makes every individual unique; analysing the ossicles of a single specimen would therefore give inconclusive results.

Disc diameters were measured with a digital calliper to the nearest decimal, from the disc edge at an arm base across to the opposite interradial. Colour patterns were recorded on preserved material, with most specimens being stored in ethanol, but some being dry. The terminology for the oral papillae follows Hendler (2018), but for better readability, we applied the term in a wider sense as the series of papillae along a jaw edge, from Lyman's ossicle to infradental papillae (but excluding tooth papillae). In the strict sense, oral papillae arise from the oral plate (= jaw) and Lyman's ossicle is not a true oral papilla, but part of the peribuccal skeleton (Hendler 2018). All type specimens of the new species with current and previous museum catalogue numbers and field numbers (as appropriate) are listed in Supplementary File 1 .

\section{Abbreviation}

$\mathrm{dd}=$ disc diameter

\section{Institutional acronyms}

NHMD $=$ Natural History Museum, Copenhagen

$\mathrm{SMNH}=$ Swedish Museum of Natural History, Stockholm

$\mathrm{ZMH}=$ Zoological Museum, Hamburg

\section{Results}

To resolve the species complex, we first delimited the type species of the genus, Ophioderma longicauda, by describing its here-selected neotype as the baseline for comparison with all other species. Then we treated each species in geographical order from west to east. Table 1 summarises the key characters that distinguish the five species. Fig. $2 \mathrm{~F}$ shows the interpretation of the oral papillae series according to Hendler (2018) as reference for all species.

Class Ophiuroidea Gray, 1840

Order Ophiacanthida O'Hara et al., 2017

Suborder Ophiodermatina Ljungman, 1867

Family Ophiodermatidae Ljungman, 1867

Genus Ophioderma Müller \& Troschel, 1840

\section{Type species}

Ophioderma longicauda (Bruzelius, 1805).

\section{Type locality}

Mediterranean Sea.

\section{Diagnosis}

Disc with dense granule cover dorsally and ventrally, including jaws; oral shields (and in some species adoral shields) naked. Arm spines numerous, up to half arm joint length. Multiple dorsal arm plates present in several species. Two short genital slits to each bursa. Single rows of numerous oral papillae. 


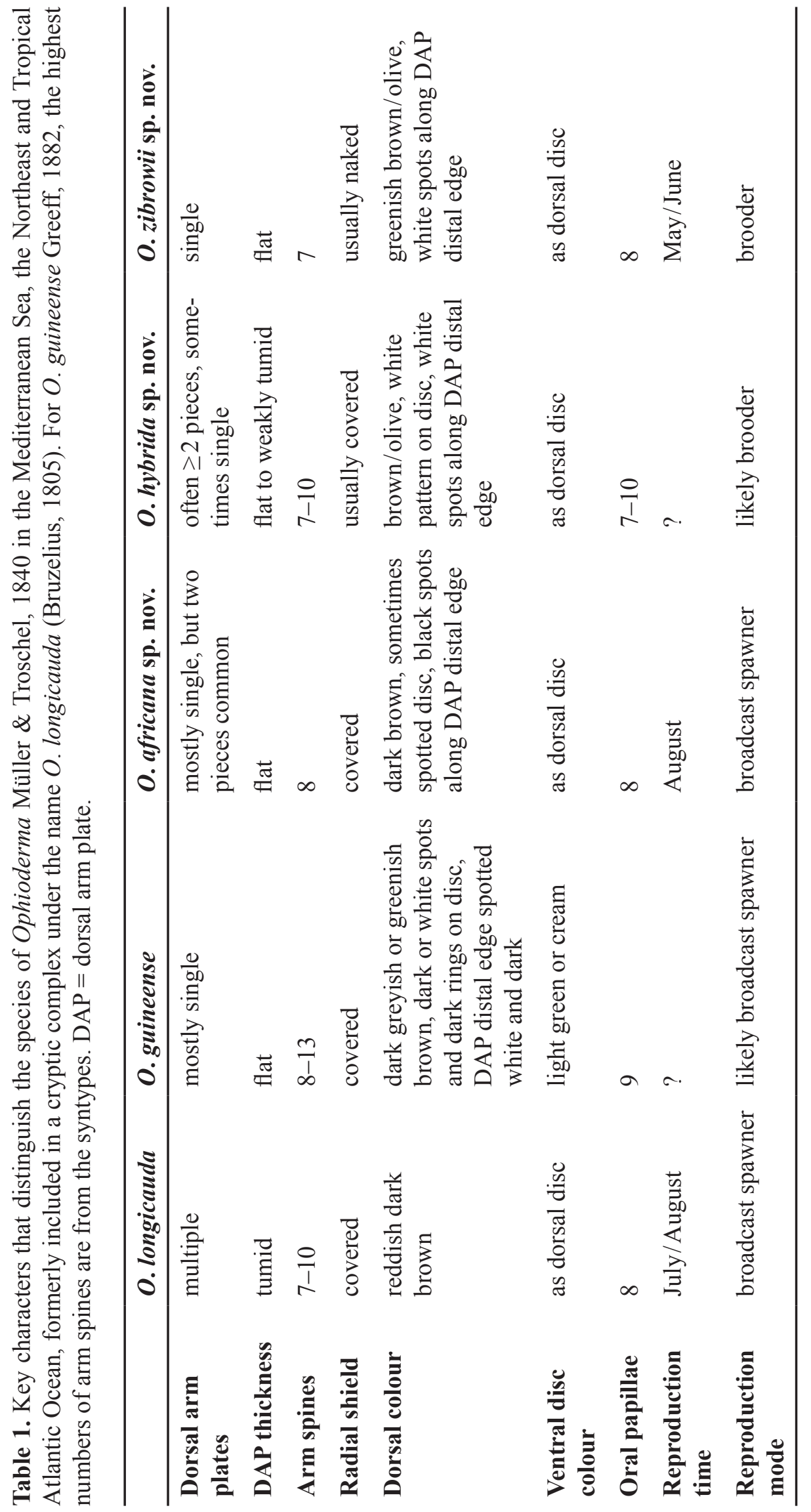


Lyman's ossicle present. Oral plate ridge spines present. Dental plate in several pieces, with nonperforating sockets of two types, round and small for tooth papillae, wide slit-like for teeth. Dissociated radial shield triangular, with distal abradial process, large internal pore and several smaller external pores. Lateral arm plates with two short spurs on the outer proximal edge and corresponding spurs on the inner distal edge. Adradial genital plate elongated, curved, proximal end with depression and round knob. Abradial genital plate flat, trapezoidal, about half as long as adradial plate.

\section{Remarks}

Multiple dorsal arm plates are known from several species of Ophioderma and previous authors have assumed that they developed by division or fragmentation (Ziesenhenne 1955; Hendler et al. 1995). Hendler (2018) questioned this assumption because the morphogenesis of these plates is not yet known and recommended microstructural analysis of the stereom. Although this question lies outside the scope of this study, we have made some observations that may help to understand the process. In young specimens of all studied species, all joints are covered by a single wide dorsal arm plate. In larger specimens, additional plates appear on the proximal (= oldest) joints and they align as if they were a single plate. Thin hair-like cracks were observed on some joints in smaller specimens with otherwise entire plates. The number of plates increases on the basal joints and distalwards with growth. There does not seem to be a pre-determined division plane and the split can occur along the mid-longitudinal of the first-formed plate or offset to left or right, seemingly at random. The separate plates appear to continue to grow, obtaining various shapes, and all their edges become rounded. When the number of plates increases, a mosaic pattern appears where plates are no longer aligned across the arm, and it may be difficult to decide to which arm joint a particular plate belongs. Fragmentation seems a plausible explanation for the formation of multiple plates that replace the first plate. The additional plates that are not in line with the original plate may form either independently or from additional divisions. Ziesenhenne (1955) suggested that broken arm plates may be the result of mechanical injury from falling stones, and this may be an alternative explanation for the existence of multiple arm plates or there may be two mechanisms at work. Possibly, only multiple plates on proximal arm joints should be considered as species-specific characters, whereas the occurrence of a few cracked plates further out on the arms is more likely the result of injury. Due to these open questions, we have refrained from using the terms fragmentation or division when describing the multiple dorsal arm plates. With regard to dental plates, Hendler (2018) found that fragmentation occurs in one species of Ophioderma, and it is likely that this applies to the whole genus.

Ophioderma longicauda (Bruzelius, 1805)

Figs 2-3; Table 1

Asterias longicauda Bruzelius, 1805: 28-29.

Ophioderma longicauda - Müller \& Troschel 1842: 86.

\section{Diagnosis}

Multiple tumid proximal dorsal arm plates, up to 10 (usually fewer) arm spines, up to eight oral papillae (counting from and including Lyman's ossicle but excluding tooth papillae, see Fig. 2F). Dorsal disc uniformly dark reddish brown or olive, dorsal arms uniformly dark or weakly banded, ventral disc as dark as dorsal disc, ventral arms and oral frame lighter coloured. Disc diameter up to $30 \mathrm{~mm}$. 


\section{Material examined}

Neotype (here designated)

MEDITERRANEAN SEA - +; France, Marseille, E of Isle Maïre; depth 6-8 m; 7 Aug. 2004; H. Zibrowius leg.; under stones; scuba diving, hand collecting; preserved in 95\% ethanol; SMNHType-8729.

\section{Other material}

MEDITERRANEAN SEA $\cdot 37$ specimens (each specimen in separate plastic bag, numbered); same data as for neotype; SMNH-102357 • 62 specimens (not used for DNA sequencing); France, E of Marseille, Port d'Alon; depth 3-15 m; 26 May 2006; H. Zibrowius leg.; under stones; scuba diving; preserved in ethanol; SMNH-81012 1 specimen $(\mathrm{dd}=12 \mathrm{~mm})$, dry ossicles; same data as for preceding; SMNH112871 - ossicles on SEM stub (from SMNH-112871); same data as for preceding; SMNH-133258 • 1 specimen $(\mathrm{dd}=15.5 \mathrm{~mm}$, mitochondrial COI lineage $\mathrm{L} 1$, nuclear cluster $\mathrm{C} 3)$, dry ossicles, ossicles on 2 SEM stubs; same data as for preceding; SMNH-160226 4 specimens; Tunisia, Tabarka; $36^{\circ} 57.27^{\prime} \mathrm{N}$, $8^{\circ} 45.48^{\prime}$ E; Jul. 2013; A. Weber leg.; hand collecting; preserved in $95 \%$ ethanol; SMNH-147063 to 147066 • 13 specimens (mitochondrial COI lineage L1, nuclear cluster C3); Greece, Crete; May 2012 (kept in aquarium, killed Mar. 2013); A. Weber leg.; preserved in 95\% ethanol; SMNH-147069.

\section{Description}

\section{Neotype (Fig. 2)}

Disc diameter $22.5 \mathrm{~mm}$; five arms, one cut for molecular analysis, one regenerating close to disc (recognizable by abrupt change in arm width; Fig. 2A, D), two regenerating close to tip. Dorsal disc, including all radial shields, completely covered by small round granules (Fig. 2A). Disc scales and granules crowd onto proximal arms, covering first few joints completely, following three joints laterally (Fig. 2C-D). Proximal dorsal arm plates thick, robust, slightly tumid, several pieces of variable size placed irregularly on each arm joint, fewer pieces distalwards and on regenerating parts (Fig. 2C). Entire dorsal plates on distal arm rounded fan-shaped, distal edge wider than proximal, twice as wide as long. Small granules, similar to disc granules, between arm plates along the arm (Fig. 2C-D). Arm joints about three times as wide as long proximally. Two to seven flat, blunt arm spines at ventral to ventro-lateral distal edge of lateral arm plate (from first spine-bearing joint under disc to proximal free ones), half as long as joint. Ventralmost spine longer and wider than others (Fig. 2B, E). Small scales at dorsolateral distal edge of lateral arm plate on some arms, few tiny scales and some granules on others. Scattered granules along spine articulations/bases of spines.

Ventral disc covered with granules similar to dorsal disc (Fig. 2B, E). Bursal slits divided into short proximal part, reaching from oral shield to second arm joint, and distal part reaching from fourth joint to disc edge (Fig. 2B, E-F). One interradius cut open. No juveniles in bursae; gonads small, with few oocytes, light brown. Adoral shields covered by granules, larger than on disc, conical (Fig. 2F). Adoral shield long, narrow, extending around the lateral edge of the oral shield, separating it from the arm. Four oral shields, rounded triangular, almost twice as wide as long, with obtuse proximal angle, convex distal edge, obtuse lateral angles, small central compression. Madreporite irregularly oval, almost as long as wide, larger central depression. Large, rectangular teeth. On either side of jaw a line of eight papillae: Lyman's ossicle large, 2.5-3 times as wide as high, angled upwards, first adoral shield spine rounded bicuspid, as wide as long, second adoral shield spine indistinguishable from other five conical, pointed lateral papillae (including infradental papilla) at oral plate edge, two tooth papillae at jaw tips in line with oral papillae, larger than oral papillae (Fig. 2F). First ventral tooth in median position above tooth papillae, rectangular with straight edges. Second oral tentacle pore hidden in oral slit.

Granules from adoral shields continue laterally along the first arm joints, decreasing in size, meeting the granules from dorsal disc at arm base, becoming indistinguishable from them (Fig. 2E). First ventral 
arm plate smaller than following plates, proximally convex, distally narrowing to a point, touching second plate. Second and following proximal ventral arm plate axe-head shaped pentagonal, thick to slightly tumid, distal edge variable concave, straight or convex, proximal edge with angle, lateral edges excavated concave. Lateral excavations decrease in depth along arm. Two oval shaped tentacle scales, superimposed on the ventralmost spine, articulating to the lateral arm plate, fitting into excavation in lateral edge of ventral arm plate.

Dark brown colour on dorsal disc and arms, ventral disc dark, ventral arms and oral frame light brown to cream (Fig. 2A-B).

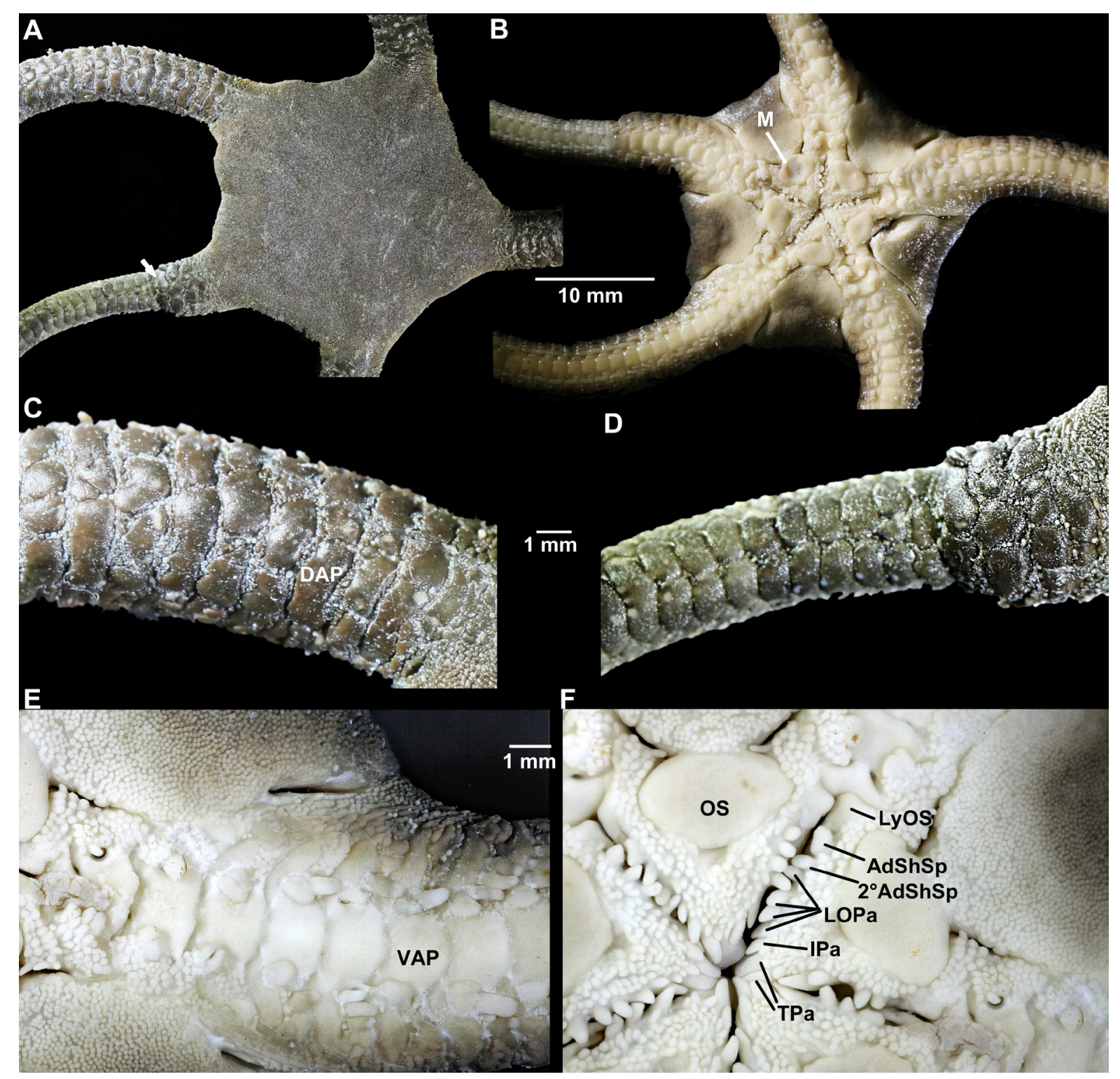

Fig. 2. Ophioderma longicauda (Bruzelius, 1805), neotype (SMNH-Type-8729), digital images. A. Dorsal disc and arm bases, arrow points to regenerating part. B. Ventral disc and basal arms. C. Basal dorsal arm, note the multiple dorsal plates. D. Regenerating arm, dorsal plates already more than one. E. Ventral arm base. F. Jaws. Abbreviations: $2^{\circ} \mathrm{AdShSp}=$ second adoral shield spine; AdShSp = adoral shield spine; DAP = dorsal arm plate; IPa = infradental papilla; $\mathrm{LOPa}=$ oral papillae; LyOS = Lyman's ossicle; $\mathrm{M}=$ madreporite; $\mathrm{OS}=$ oral shield; $\mathrm{TPa}=$ tooth papillae; $\mathrm{VAP}=$ ventral arm plate. 
Skeletal elements (Fig. 3)

Non-type specimen of $15.5 \mathrm{~mm}$ dd (SMNH-160226), morphologically similar to neotype, e.g., radial shields covered by granules. Several dorsal arm plates per joint on at least seven proximal arm joints, on many more on some arms. Radial shields isosceles triangular with strongly concave abradial edge and distal abradial process, external distal half domed with slightly finer mesh stereom and scattered small pores (the domed part is not covered by scales but with granules in the intact animal, all other areas are covered by scales). Two larger pores on distal part, adjacent to rough patch, and circle of medium-sized pores bordering domed part (Fig. 3A, C). Internally, radial shield with distal groove and two weakly domed bulbs, two pores in center of proximal half (Fig. 3B). Dental plates as varying numbers of pieces, sockets for teeth and apical tooth papillae not penetrating, bordered by low ridges (Fig. 3D). At the ventralmost edge of the dental plate, a row of small pores, probably granule articulations, followed by a row of three small round articulations for tooth papillae, the median one slightly higher than the lateral ones, followed by a row of two or a single larger round articulation and from then on single wide slit-like tooth articulations. Adradial genital plate blade-like flat with bulbous distal end and large pore, distal pit with knob on one side, three knob-like ridges on other side (Fig. 3E-F, N-O). Abradial genital plate much smaller and scale-like flat, distally wider than proximally (Fig. 3G). Oral plates longer than high, only slightly lower in central part than at proximal end, with large adradial muscle fossa with finer mesh stereom than remaining ossicle (Fig. 3H), conspicuous s-curved suture line crosses foot basin (Fig. 3I). Row of five small pores and depressions near lower edge of adradial proximal oral plate as articulations of oral papillae; four pores at proximal ventral edge of oral plate as articulations of granules (Fig. 3I). Adradial distal muscle fossa ventrally wide, tapering dorsalwards, almost vertical, shorter than height of oral plate. Large basin of first tube foot. Vertebrae typically zygospondylus, with large dorsal and small ventral muscle flanges, faint growth rings (Fig. 3J-K). Lateral arm plates compact, weakly curved around the arm, strongly convex distally, concave proximally, with ventral excavation for tube foot opening (Fig. 3L-M). Two spurs at proximal external edge and counterparts on internal distal edge of lateral arm plates. Internal lateral arm plate with vertical row of three pores just below the plate centre, slightly bent, flat vertical proximal ridge and ventral small protruding knob. Spine articulations inset in the distal plate edge with one thickened lobe, separating muscle and nerve opening.

Non-type specimen of $12 \mathrm{~mm}$ dd (SMNH-133258), adradial genital plate in lateral view with large distal pore and distal knob (Fig. 3N-O). Radial shield with irregular edges and abradial edge not concave, other characters similar to larger specimen (Fig. 3P).

\section{Remarks}

In southern France, at Marseille, only one genetic cluster of $O$. longicauda exists according to our analyses and it is safe to assume that the whole population belongs to the same species. The specimen chosen as neotype is a female for the purpose of comparison with brooders. It was selected from the samples used in Boissin et al. (2011). As one of the larger specimens in our collection, it was chosen to demonstrate the superior size of this species compared to the brooders. The species reaches a size of up to $30 \mathrm{~mm}$ dd (Stöhr et al. 2009) in the western population, but these large specimens are rare and none was included in the molecular studies. Most are well below $20 \mathrm{~mm}$ dd and the eastern population seems to stay slightly smaller with a maximum of $25 \mathrm{~mm}$ dd found (Weber et al. 2014). Internal ossicles were taken from a smaller specimen because this is the most common and easily available size in all studied species. It is important to compare individuals of similar size, since most characters are size dependent.

The highest number of arm spines recorded for O. longicauda is 10 and this character is only weakly correlated to size (Stöhr et al. 2009). The radial shields are covered by granules in the majority of examined specimens of $O$. longicauda in the western population (Stöhr et al. 2009) and in all examined specimens of this species in the eastern population (Weber et al. 2014), which makes this character fairly reliable to differentiate $O$. longicauda from sympatric $O$. zibrowii sp. nov., although specimens with 


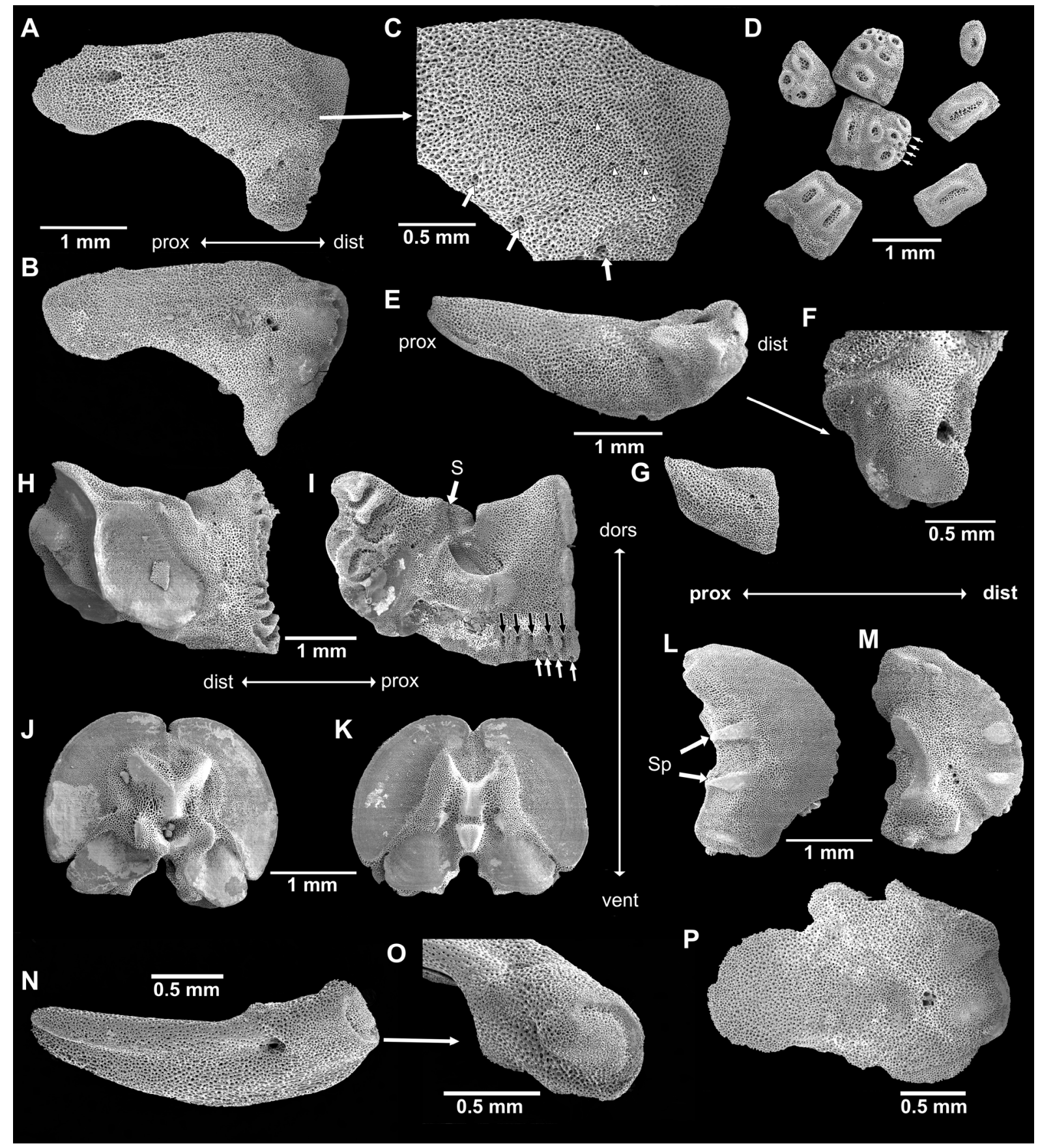

Fig. 3. SEM images of skeletal elements of Ophioderma longicauda (Bruzelius, 1805). A-M. Non-type specimen of $15.5 \mathrm{~mm}$ disc diameter (SMNH-160226). A. Radial shield, external aspect. B. Radial shield, internal aspect. C. Scale-free area of Fig. 3A magnified, white arrowheads point to granule sockets and pores, white arrows point to large peripheral pores. D. Dental plate fragments, arrows point to granule pores. E. Adradial genital plate. F. Articulation knobs of Fig. 3E. G. Abradial genital plate. H. Oral plate, abradial face. I. Oral plate, adradial face, black arrows point to oral papillae sockets and pores, white arrows point to granule socket pores. J. Arm vertebra, proximal face. K. Arm vertebra, distal face. L. Lateral arm plate, external face. M. Lateral arm plate, internal face. $-\mathbf{N}-\mathbf{P}$. Non-type specimen of $12 \mathrm{~mm}$ disc diameter (SMNH-133258). N. Adradial genital plate, lateral view. O. Adradial genital plate, distal end. P. Radial shield, internal aspect, note the different shape from Fig. 3A-B. Abbreviations: dist $=$ distal; dors $=$ dorsal; prox $=$ proximal; $\mathrm{S}=$ suture line; $\mathrm{Sp}=$ spurs; vent $=$ ventral. 
covered radial shields have been found in the latter. The radial shields are a key character to distinguish these two species. In the intact animal, scales cover most of the radial shield, except for the domed distal area that becomes visible only after the radial shield has been isolated by dissociation of the skeleton in bleach. Granules are attached to all scales and to the unscaled part in O. longicauda. Each small pore in this area probably indicates the position of a granule. They may be nerve openings but little is known about these. The shape of the radial shield is variable between individuals but the granule articulations are the same. The domed distal part is finer meshed than the remaining areas; in O. longicauda it is not as well defined as in $O$. zibrowii sp. nov., and it is oval instead of round as in $O$. africana sp. nov. The large number and thickness of the dorsal arm plates are another character that distinguishes $O$. longicauda from all other species, but in small specimens, there is a single plate on each arm joint. For further differentiation between species, see below.

Ophioderma guineense Greeff, 1882

Figs 4-6; Table 1

Ophioderma guineense Greef, 1882: 156.

Ophioderma longicauda var. guineense - Koehler 1914: 173.

Ophioderma longicauda guineense - Madsen 1970: 225, fig. 43.

“Ophioderma appressa?" - Koehler 1914: 175; Madsen 1970: 228.

\section{Diagnosis}

Predominantly single flat dorsal arm plates, up to 13 arm spines, nine oral papillae (counting from and including Lyman's ossicle but excluding tooth papillae). Colouration in alcohol variable, dorsal disc brown with white spots and dark rings, arms banded dark and light brown to grey, ventral disc, arms and oral frame cream to light grey, dark and white spots along distal edge of dorsal arm plates. Disc diameter of largest paralectotype $29 \mathrm{~mm}$.

\section{Material examined}

Lectotype (here designated) TROPICAL ATLANTIC OCEAN • West Africa, Gulf of Guinea, Islands Sao Tomé and Rolas; cliffs at low tide; ZMH E8315.

Paralectotypes (here designated)

TROPICAL ATLANTIC OCEAN $\bullet 6$ specimens $(2$ specimens at hand, 4 specimens examined on photographs); same data as for lectotype; ZMH E1686.

\section{Other material}

TROPICAL ATLANTIC OCEAN • 11 specimens (photographed specimens in separate bags labelled as \#1-3, mitochondrial lineage L6, nuclear cluster C1); Senegal, Dakar, Grand Thiouriba; depth 38 m; 6 Sep. 2007; H. Zibrowius leg.; from heavily fouled piece of fishing net; scuba diving, hand collected; preserved in 95\% ethanol; SMNH-95511 1 specimen $(\mathrm{dd}=11.7 \mathrm{~mm})$, dried arm pieces, dried ossicles, ossicles mounted on two SEM stubs; same data as for preceding; SMHN-178429 3 specimens (labelled as O. longicauda var. guineense); Equatorial Guinea, Gulf of Guinea, Annobón; depth 18-30 m; Discovery exped. (stn 283); dried; NHMD-225525.

\section{Description}

Lectotype (Fig. 4A-D)

Disc diameter $28.5 \mathrm{~mm}$, radial shields widely separated, sunken in, concealed by granules. Scales and granules crowd onto proximal arms, obscuring dorsal plates laterally, granules rubbed off in some 


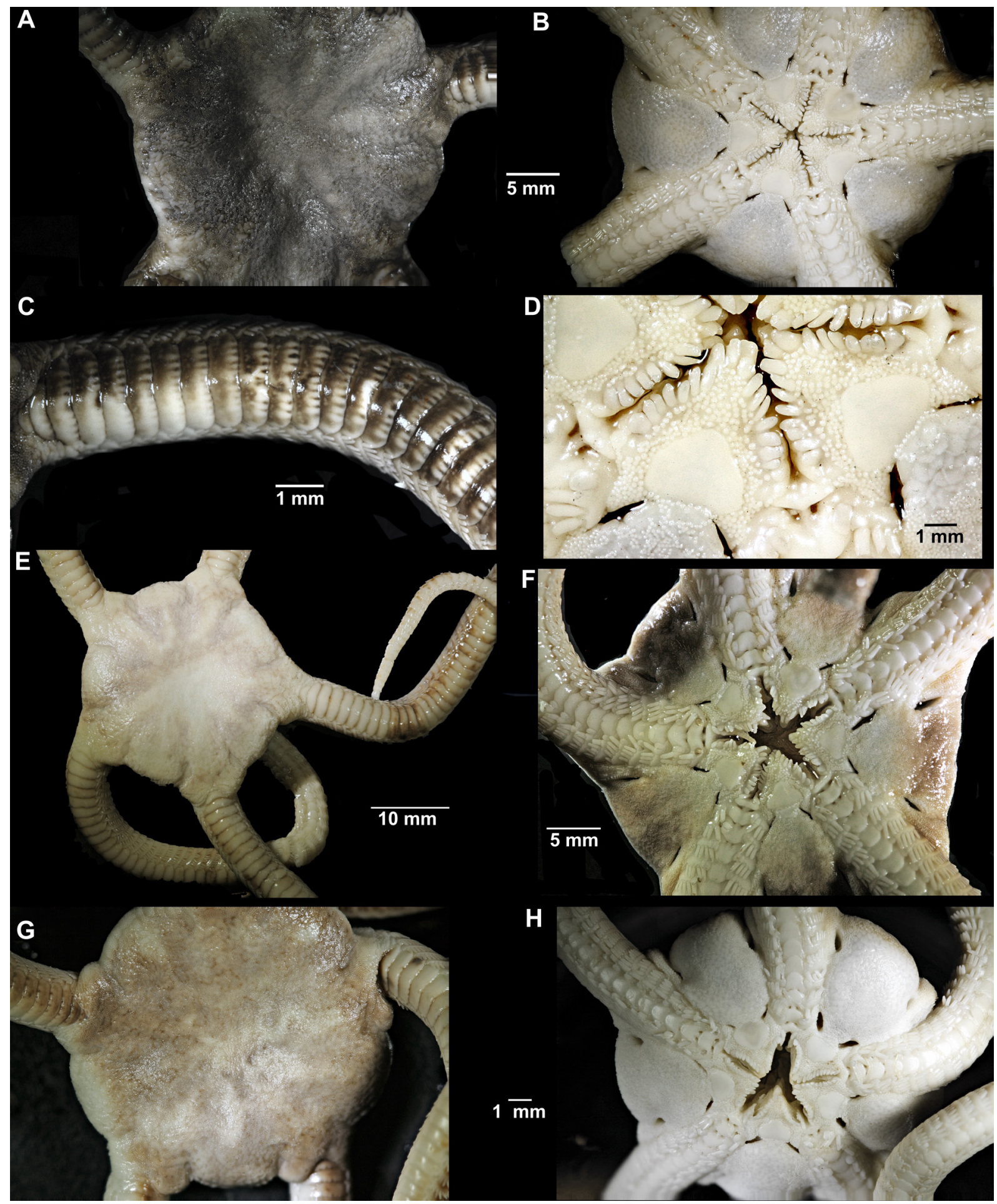

Fig. 4. Ophioderma guineense Greef, 1882, type specimens, digital images. A-D. Lectotype (ZMH E8315). A. Dorsal disc. B. Ventral disc. C. Dorsal arm. D. Jaws. - E-F. Paralectotype (ZMH E1686). E. Dorsal aspect. F. Ventral aspect. - G-H. Other paralectotype (ZMH E1686). G. Dorsal aspect. H. Ventral aspect. 
places. Dorsal arm plates entire almost on whole arm (single cracked plates on mid-arms), not tumid, three times as wide as long, contiguous (Fig. 3C). Three to 13 arm spines (from first spine bearing joint under disc to proximal free ones), flattened, slightly pointed, slightly longer than half arm-joint length, ventralmost spine longer and wider than others. Ventral arm plates wider than long, with convex distal edge, overlapping, except the proximalmost 3-4 which are separated by pores. Two oval scale-like tentacle scales, superimposed on the ventralmost spine.

Ventral disc covered by granules similar to dorsal disc (Fig. 4D). Lyman's ossicle elongated, reaching into the mouth slit, not obvious, adoral shield spines on some jaw edges block-like, on others as lateral papillae and not obvious, in total nine oral papillae per jaw edge. Two tooth papillae at jaw tips in line with oral papillae, slightly larger than oral papillae. Teeth rectangular with straight edges. Oral shields rounded triangular with obtuse proximal angle and straight distal edge, slightly wider than long. Madreporite larger than other oral shields, depressed. Adoral shield long, narrow, extending around the lateral edge of the oral shield, separating it from the arm. Adoral shields covered with granules, similar to disc in size.

Colour pattern with tiny dark spots on the dark grey-brown dorsal disc, dark and white spots on the distal edge of the dorsal arm plates, cream ventral side (Fig. 4A-C).

Paralectotypes (Fig. 4E-H)

Disc diameter 26 and $29 \mathrm{~mm}$, both with up to 13 arm spines, 9-10 oral papillae. Radial shields concealed by granules, but in parts of the disc, the granules have been rubbed off (Fig. 4E, G). Proximal dorsal arm plates entire. In the largest syntype, colour faded light brown dorsally, cream with some dark brown ventrally, arms with faint dark bands. There are irregular dark rings on the pale brown dorsal disc of the smallest syntype examined (Fig. 4G). In these specimens, there are dark brown and white spots along the distal edge of the dorsal arm plates. Among the paralectotypes examined only from photographs, one is dark brown on dorsal disc and arms, and the dark colour extends onto the ventral disc, fading towards the oral frame. The other specimens have a faded brown dorsal colour and light ventral discs and arms. Some of these show faint spots on distal edges of the dorsal arm plates.

The amplification of nuclear markers from the syntypes was not successful, most likely due to the long storage time and unknown initial preservation method of the specimens, which might have caused the DNA to deteriorate.

\section{Specimen from Senegal (SMNH-95511\#1, Fig. 5A-D)}

Disc diameter $15 \mathrm{~mm}$, up to nine arm spines proximally, dorsal arm plates flat, entire along whole arm, radial shields covered by granules. Disc scales with granules crowding onto arm base, covering first dorsal arm plate except for a mid-distal portion, second plate also covered by scales and granules laterally. Dorsal arm plates overlapping, twice as wide as long, rounded fan-shaped, distal edge wider than proximal, not tumid. Ventral disc covered by similar granules as dorsal disc. Jaws with nine lateral papillae. Two larger tooth papillae at jaw tips in line with oral papillae, rectangular teeth with straight edges. Oral shields triangular, almost as long as wide. Adoral shield long, narrow, extending around the lateral edge of the oral shield, separating it from the arm. Adoral shields covered with granules similar in size to disc granules. Proximal genital slits small, extending from oral shield to proximal edge of second ventral arm plate. Distal genital slits at disc edge, next to fifth arm joint.

Disc dark brown dorsally, large white patches in centre. All over with small irregular white dots with black margins (ring-like). Disc light green ventrally. Oral shields with darker green centres. Arms dorsally dark brown, with lighter and darker bands, ventrally cream white with faint darker bands. Dorsal arm plates with small black spots along distal edge. 


\section{Variation in other Senegalese specimens}

Size range $8-13 \mathrm{~mm}$ dd. The specimens vary in colour pattern. One specimen has large white patches over the area around the radial shields, on an otherwise dark disc. Some animals have a light brown disc with minute, irregular white spots with black borders (SMNH-95511\#2, Fig. 5E-F) or a greyish green disc with black rings (SMNH-95511\#3, Fig. 5G-I). Dorsal arms banded light and dark, distal edge of dorsal arm plates with small dark and white spots. The ventral disc is always much lighter than the dorsal disc, often cream with a hint of darker colour, sometimes green. The oral shields are completely creamy white in some specimens. Ventral arms are cream. Some specimens with only up to eight oral papillae.

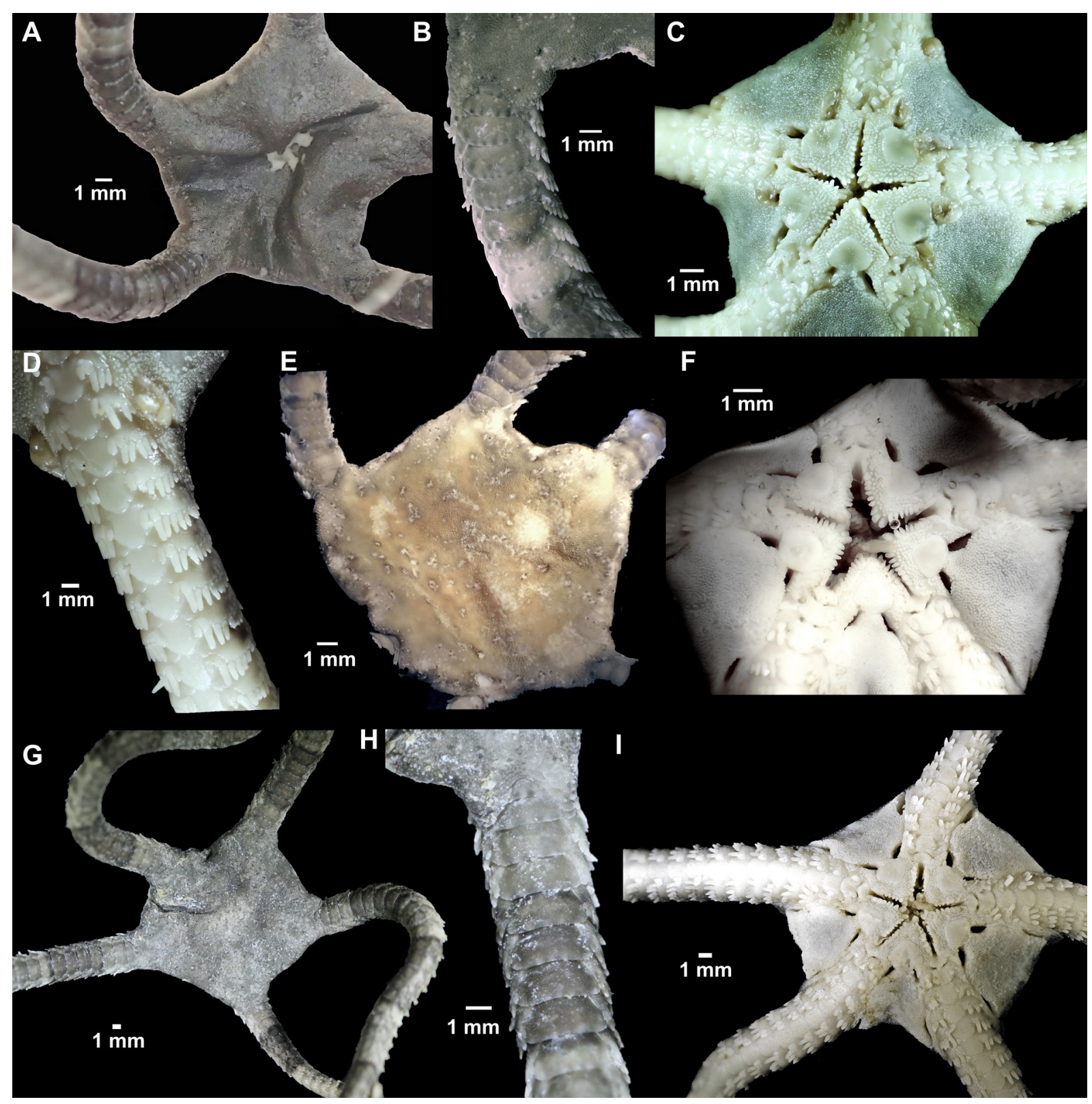

Fig. 5. Ophioderma guineense Greef, 1882, material from Thiouriba, Senegal, digital images. A-D. Dark brown specimen with light green ventral side (SMNH-95511\#1). A. Dorsal aspect. B. Dorsal arm. C. Ventral aspect. D. Ventral arm. $-\mathbf{E}-\mathbf{F}$. Light brown specimen with spotted disc and white ventral side (SMNH-95511\#2). E. Dorsal aspect. F. Ventral disc. - G-I. Grey-brown specimen with spotted disc and white ventral side (SMNH-95511\#3). G. Dorsal aspect. H. Dorsal arm. I. Ventral aspect. 


\section{Skeletal elements (Fig. 6)}

From specimen with $11.7 \mathrm{~mm}$ dd (SMHN-178429). Radial shield at widest part about as wide as long, isosceles triangular with abradial projection and convex radial edge, externally with domed center with finer mesh stereom (the domed part is not covered by scales but with granules in the intact animal, all other areas are covered by scales), a circle of pores around domed part, two large pores on the proximal end (Fig. 6A, C). Internally, radial shield with large pore in center of distal half, adjacent to rough patch, distally two knobs, radial one larger, separated by a furrow (Fig. 6B). Dental plates as varying numbers of pieces, sockets for teeth and apical tooth papillae not penetrating, bordered by low ridges, tooth papillae sockets small round, tooth sockets wider oval (Fig. 6D). Adradial genital plate blade-like flat with bulbous distal end and large pore, distal pit with knob on one side, three ridges

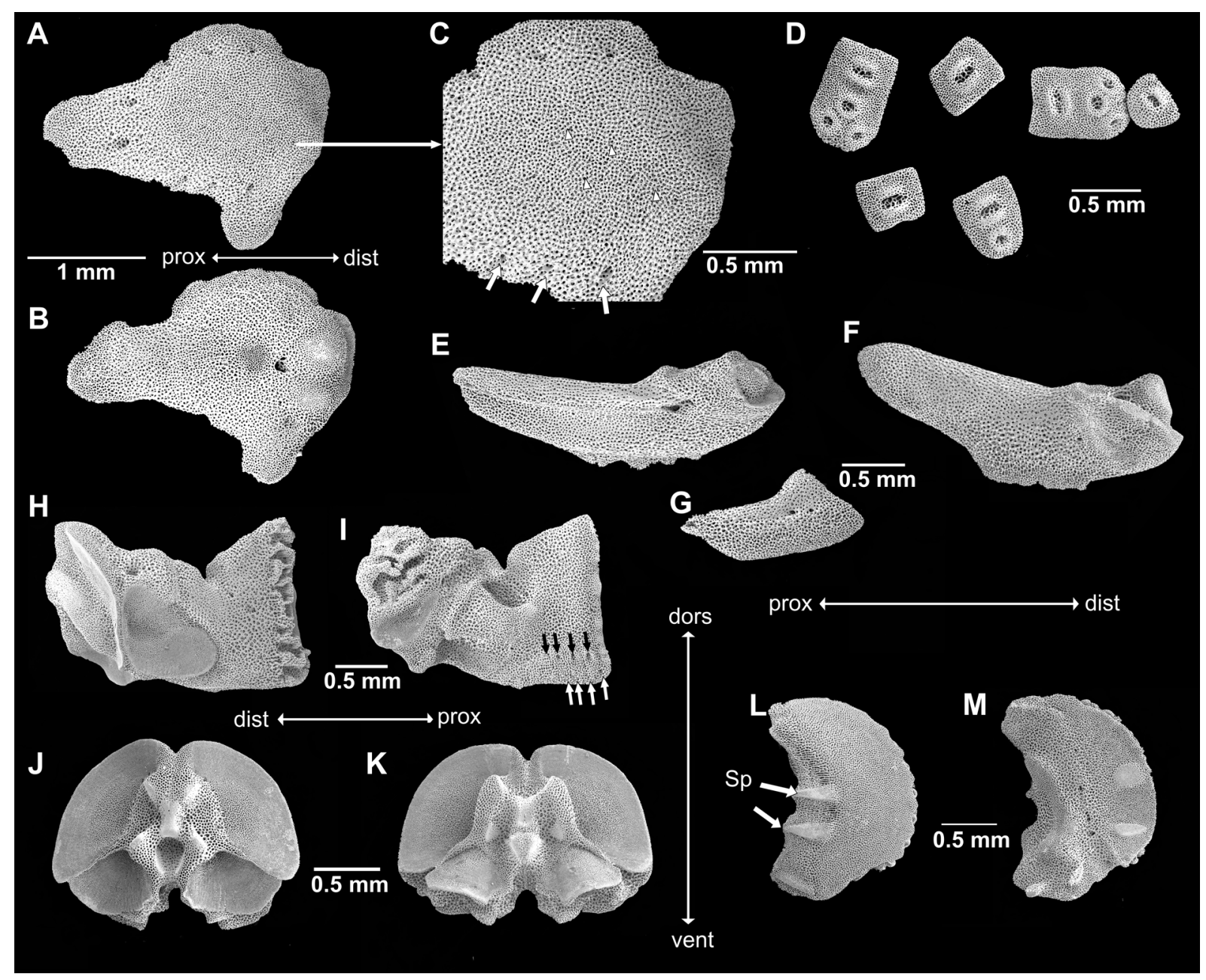

Fig. 6. SEM images of skeletal elements of Ophioderma guineense Greef, 1882, Thiouriba, Senegal, from specimen of $11.7 \mathrm{~mm}$ disc diameter (SMHN-178429). A. Radial shield external. B. Radial shield internal. C. Scale-free area magnified from Fig. 6A, white arrowheads point to granule sockets and pores, white arrows point to larger peripheral pores. D. Dental plate fragments. E-F. Adradial genital plate, two opposite lateral aspects. G. Abradial genital plate. H. Oral plate, abradial face I. Oral plate adradial face, black arrows point to oral papillae sockets and pores, white arrows point to granule socket pores. J. Arm vertebra proximal face. K. Arm vertebra distal face. L. Lateral arm plate, external face. M. Lateral arm plate, internal face. Abbreviations: dist $=$ distal; dors $=$ dorsal; prox $=$ proximal; $\mathrm{Sp}=$ spurs; vent $=$ ventral. 
on other side (Fig. 6E-F). Abradial genital plate much smaller and scale-like flat, distally wider than proximally (Fig. 6G). Oral plates longer than high, middle part markedly lower than ends, abradial muscle fossa rounded triangular with depression in upper half, not reaching upper edge (Fig. $6 \mathrm{H})$. On adradial oral plate proximoventral part four oral papilla sockets and pores, at proximoventral edge four indistinct granule sockets and pores (Fig. 6I). Vertebrae zygospondylous, with large wing-like muscle fossae (Fig. 6J-K). Lateral arm plates compact, weakly curved around the arm, strongly convex distally, concave proximally, with ventral excavation for tube foot opening (Fig. 6L, M). Two spurs at proximal external edge and counterparts on internal distal edge of lateral arm plates. Internal lateral arm plate with vertical row of three pores just below the plate centre, fourth pore in tentacle opening edge, bent vertical proximal ridge and small ventral knob, protruding beyond plate edge. Spine articulations inset in the distal plate edge with one thickened lobe, separating muscle and nerve opening.

\section{Remarks}

Ophioderma guineense was until now considered conspecific with O. longicauda. It differs from O. longicauda in having mainly single and flat dorsal arm plates and a higher number of arm spines (Table 1). A previously unrecognized differentiating character is the light colouration of the ventral side of $O$. guineense, in contrast to the dark colour of $O$. longicauda, and the spots on the distal edge of the dorsal arm plates, which are absent in $O$. longicauda. Considering the small morphological differences between the genetic clades in the species complex of $O$. longicauda, we propose to treat $O$. guineense as a valid species and we consider the recently collected specimens of genetic cluster $\mathrm{C} 1$ as conspecific due to their colouration and mostly single dorsal arm plates. The specimens of NHMD-225525 also concur with this assignment. As lectotype, we selected a specimen that concurs well with the original description (Fig. 4A-C): Greef (1882) described the colouration of his specimens as on the dorsal disc blackish or dark brown, ventrally light green, the arms dorsally black with grey white rings, ventrally grey yellow, which fits with the material from Senegal (Fig. 5). There are irregular dark rings on the pale brown dorsal disc of the smallest paralectotype examined (Fig. 4G) and tiny dark spots on the dark grey-brown dorsal disc of the lectotype (Fig. 4A), both have cream ventral discs and arms (Fig. 4B, H). The largest of the examined paralectotypes has a faded brown dorsal disc and also some dark brown pigmentation remaining on the ventral disc (Fig. 4E-F); one of the specimens seen only on photographs has a dark dorsal disc and dark pigment on the ventral disc, quite similar to $O$. africana sp. nov. (see below, Fig. 7). Based on colour pattern, there may be a possibility that the type specimens are conspecific with $O$. africana sp. nov. However, in addition to differences in colour, multiple dorsal arm plates are more common in $O$. africana sp. nov. than in O. guineense, which has led us to assign the Senegal specimens to $O$. guineense.

Colour pattern tends to vary in most species of Ophioderma (Hendler et al. 1995) but O. guineense differs notably from all species observed by this study from Mediterranean and East Atlantic localities (over 800 specimens in the collection of SMNH). These may be similar in dorsal colour with uniformly brown or mottled dorsal discs, sometimes with white spots, but they always have a dark ventral disc and lighter coloured, but never white, arms and oral frames (Stöhr et al. 2009). Red pigments seem more common in $O$. longicauda than green, and the ventral arms are often either reddish or green in the Mediterranean species, with the disc being brown or olive.

No embryos have been found in specimens of $O$. guineense and this species is most likely a broadcast spawner. 


\section{Ophioderma africana sp. nov. urn:1sid:zoobank.org:act:64021157-EA56-449B-9BCB-FD02F10CC67F}

Figs 7-8; Table 1

\section{Diagnosis}

Mostly single dorsal arm plates, but several plates on some joints, eight arm spines, eight oral papillae. Colour dark brown dorsally, ventral disc as dark, ventral arms lighter brown, black and white spots along distal edge of dorsal arm plates. Maximum size under $19 \mathrm{~mm}$ dd $(26 \mathrm{~mm}$ dd if non-type material is considered).

\section{Etymology}

The species is named for its area of collection, off (West) Africa.

\section{Material examined}

Holotype

TROPICAL ATLANTIC OCEAN • Senegal, Dakar, Gorée Island, shipwreck Tacoma; depth 10 m; 28 Aug. 2007; H. Zibrowius leg.; scuba diving, hand collected; under stones; preserved in 95\% ethanol; SMNH-Type-7484.

\section{Paratypes}

TROPICAL ATLANTIC OCEAN - 22 specimens (6 sampled for both COI and nuclear markers, mitochondrial COI lineage L5, nuclear cluster C2); same data as for holotype; SMNH-Type-7485 • 1 specimen, ossicles, 4 remaining arms, 2 SEM stubs with ossicles; same data as for holotype; dried; SMNH-Type-7486 11 specimens (including a separate vial with eggs that were spawned during collection); same data as for holotype; initially in formalin, then $80 \%$ ethanol; SMNH-Type-7487 • 4 specimens (2 used for both COI and nuclear markers, mitochondrial COI lineage L5, nuclear cluster C2); Senegal, Dakar, Cap Manuel; depth 7 m; 6 Sep. 2007; H. Zibrowius leg.; under stones; scuba diving, hand collected; preserved in 95\% ethanol; SMNH-Type-7488 4 specimens ( 2 used for both COI and nuclear markers, mitochondrial COI lineage L5, nuclear cluster C2); Senegal, Madelene Islands; depth 10-12 m; 9 Sep. 2007; H. Zibrowius leg.; among piled up rocks; scuba diving, hand collecting; preserved in 95\% ethanol; SMNH-Type-9184.

\section{Other material}

TROPICAL ATLANTIC OCEAN • 6 specimens (labelled as O. longicauda); Senegal, between Gorée and Tiaroye; depth 15-20 m; Feb.-Mar. 1952; Thorson leg.; preserved in ethanol; NHMD-225514 • 6 specimens (labelled as O. longicauda); Senegal, Dakar; Jan. 1928; Sudan exped.; H. Madsen leg.; dried; partial sample; NHMD-225517 • 10 specimens (labelled as O. longicauda); Dakar; 6 Jan. 1928; Sudan exped.; H. Madsen \& O. Hagerup leg.; preserved in in ethanol; partial sample; NHMD-225523 - 1 specimen (labelled as O. longicauda); Senegal, Dakar, rocky coast; 3 Jan. 1928; H. Madsen leg.; preserved in ethanol; NHMD-225524.

\section{Description}

\section{Holotype (Fig. 7)}

Disc diameter $18.7 \mathrm{~mm}$, disc completely covered by small granules dorsally and ventrally (Fig. 7A-C), including the radial shields (Fig. 7B). Disc scales with granules crowding onto arm base, covering first dorsal arm plate except for a mid-distal portion, second plate also covered by scales and granules laterally (Fig. 7D-E). Dorsal arm plates flat, 2.5 times as wide as long, with straight distal edge, contiguous, mostly single, but joints with two plates common (often unequal in size) (Fig. 7D-E). Eight arm spines, ventralmost one thicker and slightly longer than others (Fig. 7F). Ventral disc covered by 
granules similar to dorsal disc. Eight conical oral papillae, Lyman's ossicle and adoral shield spines hardly distinguishable (Fig. 7G). Two larger tooth papillae at jaw tips in line with oral papillae, blocklike teeth. Oral shields rounded triangular, slightly wider than long, madreporite slightly wider than other oral shields and with central round depression. Adoral shield long, narrow, extending around the lateral edge of the oral shield, separating it from the arm. Adoral shields covered with granules, similar to disc in size. Proximal genital slits about one joint long, distal slits about three joints long (Fig. 7C). Ventral arm plates contiguous, as wide as long, with wide proximal angle, convex distal edge (Fig. 7F). Two oval scale-like tentacle scales, superimposed on the ventralmost spine.

Disc dark brown dorsally, with some lighter brown patches. Dorsal arms dark brown, distally lighter and banded. Dorsal arm plates with small light brown and black dots along distal edge. Ventral disc as dark as dorsal, oral frame and ventral arms light orange brown (Fig. 7A, C).

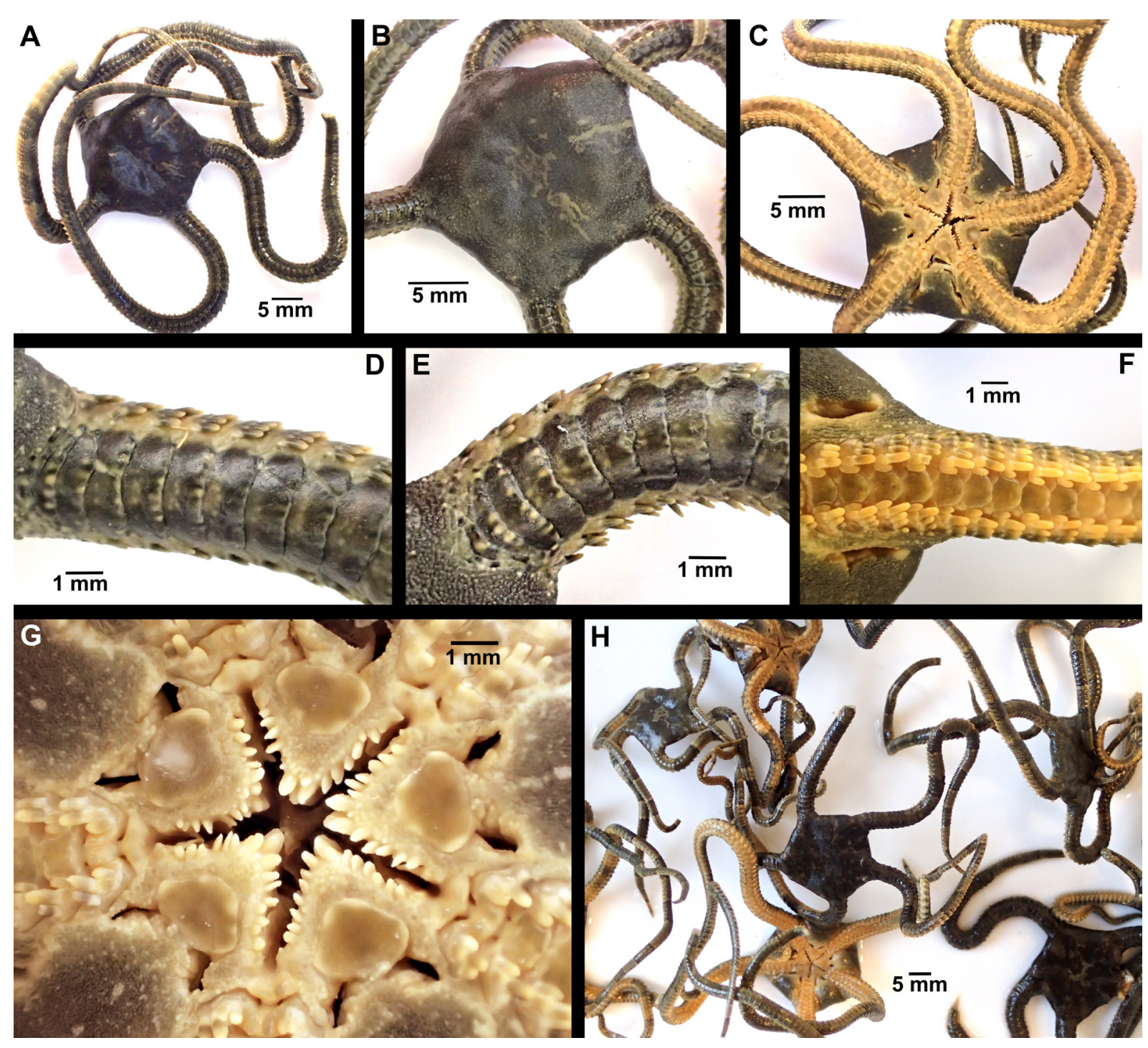

Fig. 7. Ophioderma africana sp. nov., digital images. A-G. Holotype (SMNH-Type-7484). A. Dorsal aspect. B. Dorsal disc. C. Ventral aspect. D-E. Two dorsal arms, note multiple dorsal arm plates on both. F. Ventral arm. G. Mouth. H. Some paratypes (SMNH-Type-7487). 


\section{Paratypes}

Size range 12-18.4 $\mathrm{mm}$ dd. The specimens have dark brown to almost black dorsal discs (on some individuals with lighter patches), arms with dark and lighter bands. Ventral discs as dark as dorsal, oral frames and ventral arms lighter brown (Fig. 7H). Individuals with small light spots on the disc occur. Most specimens with black dots on the distal edge of the dorsal plates, but some without. Dorsal arm plates are mostly single, but most arms with several joints with two plates.

\section{Skeletal elements (Fig. 8)}

From specimen of $15.7 \mathrm{~mm}$ dd (SMNH-Type-7486) with mostly single dorsal arm plates but some small additional plates on few joints. Seven oral papillae, all similar except Lyman's ossicle. Up to eight

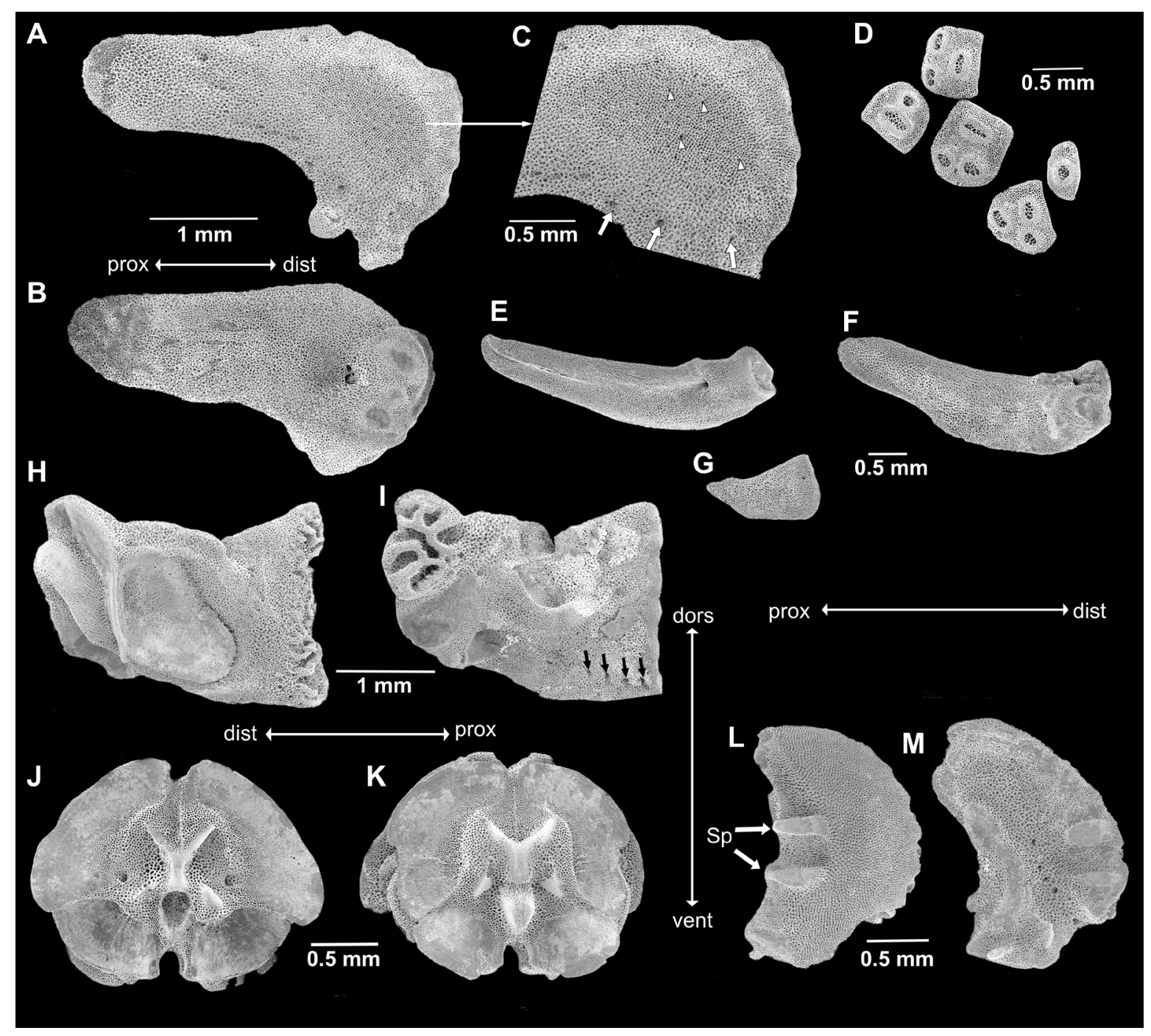

Fig. 8. SEM images of skeletal elements of Ophioderma africana sp. nov., from paratype of $15.7 \mathrm{~mm}$ disc diameter (SMNH-Type-7486). A. Radial shield, external aspect. B. Radial shield, internal aspect. C. Scale-free part magnified from Fig. 8A, white arrowheads point to granule sockets and pores, white arrows point to larger peripheral pores. D. Dental plate fragments. E-F. Adradial genital plate, two opposite lateral aspects. G. Abradial genital plate. H. Oral plate, abradial face. I. Oral plate, adradial face, black arrows point to oral papillae sockets and pores. J. Arm vertebra, proximal face. K. Arm vertebra, distal face. L. Lateral arm plate, external face. M. Lateral arm plate, internal face. Abbreviations: dist = distal; dors $=$ dorsal; prox $=$ proximal $; \mathrm{Sp}=$ spurs; vent $=$ ventral. 
arm spines. Radial shields isosceles triangular with deeply concave abradial edge and abradial distal processes, distal center domed with small pores (the domed part is not covered by scales but with granules in the intact animal, all other areas are covered by scales) (Fig. 8A, C). Inner side of radial shield, on the distal articulation surfaces, two larger oval depressions and a smaller round one between these (Fig. 8B). Dental plate consists of several pieces with non-perforating sockets for 2-3 tooth papillae and single wide teeth, granule pores not obvious (Fig. 8D). Adradial genital plate blade-like flat with bulbous distal end and large pore, distal pit with knob on one side, two distal depressions on other side (Fig. 8E-F). Abradial genital plate much smaller and scale-like flat, distally wider than proximally (Fig. 8G). Oral plates longer than high, middle part slightly lower than ends, adradially with four oral papilla pores on ventral edge of proximal part, small granule pores at ventral edge (Fig. 8I). Adradial distal muscle fossa wide ventrally, tapering dorsalwards, shorter than plate height, articulation area slightly higher than wide (Fig. $8 \mathrm{H}$ ). Suture line diagonally across oral plate mid-line, separated easily during preparation on several jaws. Vertebrae typically zygospondylus, with large dorsal and small ventral muscle flanges, no growth rings obvious (Fig. 8J-K). Lateral arm plates compact, weakly curved around the arm, strongly convex distally, concave proximally, with ventral excavation for tube foot opening (Fig. 8L-M). Two spurs at proximal external edge and counterparts on internal distal edge of lateral arm plates. Internal lateral arm plate with vertical row of three pores just below the plate centre, fourth pore in tentacle opening edge, bent vertical proximal ridge and small ventral knob, protruding beyond plate edge. Spine articulations inset in the distal plate edge with one thickened lobe, separating muscle and nerve opening.

\section{Other specimens}

The specimens from NHMD possess mostly single dorsal arm plates, on few joints there are more than one and some specimens have on the most proximal joints a mosaic of slightly tumid plates. Some specimens have naked radial shields. They have 7-9 oral papillae, among which the adoral shield spine and Lyman's ossicle are sometimes obvious, differing in shape from the other papillae. They are uniformly dark brown or variegated dark, on both dorsal and ventral sides. They range in size between 19 and $26 \mathrm{~mm}$ dd and are assigned to O. africana sp. nov. mostly by colour pattern and exclusion of O. longicauda from off West Africa. The specimen NHMD-225524, which measures only $5.7 \mathrm{~mm}$ dd, has a light brown dorsal pattern with faint spots, a cream white ventral surface, and single dorsal arm plates, similar to $O$. guineense and is reassigned to that species.

\section{Remarks}

Ophioderma africana sp. nov. shares the dark colour on both sides of the disc with O. longicauda, its spine numbers fall within the variability of both $O$. longicauda and $O$. guineense, it has as few oral papillae as $O$. longicauda (Table 1). These characters are however variable and small specimens may be difficult to identify. Nuclear and mitochondrial data were distinct from O. longicauda and all other clusters found (Weber et al. 2019), placing O. africana sp. nov. in cluster C2 and COI lineage L5. Some of the animals started spawning during collecting, which indicates that the species is a broadcast spawner, not a brooder.

$$
\begin{gathered}
\text { Ophioderma hybrida sp. nov. } \\
\text { urn:1sid:zoobank.org:act:72379251-8181-4B42-8CB6-881F0C144526 }
\end{gathered}
$$

Figs 9-10; Tables 1-2

\section{Diagnosis}

Species of Ophioderma with variable morphology. Dorsal arm plates single or as several pieces. Seven to 10 equal arm spines. Eight oral papillae. Colour pattern: disc dark brown or olive dorsally and ventrally, often with white spots. Dorsal arms dark brown with light brown or white and black spots, ventrally lighter brown. Maximum known size about $19 \mathrm{~mm}$ dd. 


\section{Etymology}

This species has likely evolved by an ancient hybridization event between two species (O. longicauda and $O$. zibrowii sp. nov. or their respective ancestors), which the Latin word hybrida alludes to. It also refers to the mixed morphology of the species.

\section{Material examined}

\section{Holotype}

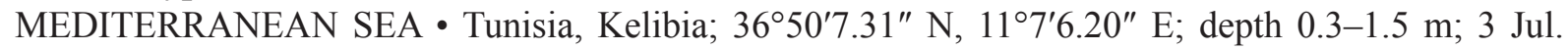
2013; Zined Marzouk \& Alexandra Weber leg.; preserved in 95\% ethanol; SMNH-Type-9185.

\section{Paratypes}

MEDITERRANEAN SEA • 11 specimens; same data as for holotype; SMNH-Type-9186 • 8 specimens; Tunisia, Monastir; 3546'28.83" N, 1050'18.93" E; depth 2-5 m; 25 Jun. 2013; A. Weber leg.; preserved in 95\% ethanol; SMNH-Type-9187.

\section{Other material}

MEDITERRANEAN SEA - 3 specimens (with dorsal disc removed, but present); same data as for holotype; SMNH-178454 - 3 specimens; Tunisia, Tunis; 1849; Åberg leg.; SMNH-35614, 123374, 123375 .

\section{Description}

\section{Holotype (Fig. 9)}

Disc diameter $17.4 \mathrm{~mm}$, two arms cut off near disc but present (Fig. 9A-B). Radial shields covered by disc granules (Fig. 9A). Dorsal arm plates weakly tumid, as 1-3 pieces on about first 30 joints, when single twice as wide as long, distal edge straight or concave (Fig. 9C-D). Ten arm spines, all about equal in length, ventralmost slightly wider. Ventral arm plates overlapping, squared, distal edge convex (Fig. 9E). Two oval scale-like tentacle scales, superimposed on the ventralmost spine. Ventral disc covered by granules similar to dorsal disc. Eight oral papillae, short, weakly pointed to round, Lyman's ossicle large, pointing into mouth slit (Fig. 9F). Tooth papillae larger than oral papillae, teeth rounded block-shaped. Oral shield almost twice as wide as long, with wide proximal angle, distal edge slightly convex. Madreporite larger, almost as long as wide (Fig. 9B). Adoral shield long, narrow, extending around the lateral edge of the oral shield, separating it from the arm (Fig. 9F). Adoral shields covered with granules, similar to disc granules. Proximal genital slits angled from oral shield to second arm joint, distal genital slits at disc edge, two arm joints long.

Disk dark brown dorsally with radiating lighter brown pattern and scattered white spots (Fig. 9A). Dorsal arms dark brown with light brown and dark spots along the distal plate edges and on some lateral edges (Fig. 9C-D). Ventral disc and arms light greenish brown, oral shields darker (Fig. 9B).

\section{Variation}

The range of morphological variation is presented in Table 2 and on Fig. 10. The specimens vary in size from 9.8 to $18.7 \mathrm{~mm}$ disc diameter. Among the 23 examined specimens, the number of dorsal arm plate pieces varies considerably. Multiple plates or pieces have been found on the proximal arms, until about joint number 30, but not on all joints, and sometimes not on all arms (Fig. 10E). In most specimens, there are only two pieces, but in a few animals, multiple pieces were observed (Fig. 10E, H, N). Some specimens have only single dorsal arm plates (Fig. 10B, K). More pieces are present in the larger specimens but there appears to be only a weak size relation for this trait. Likewise, the number of arm spines and oral papillae is not related to disc diameter. All but two animals have granule covered radial shields. Colour variations are limited. All examined specimens have a dark brown or olive dorsal disc with varying white patterning (from spots to radiating lines) and a dark ventral disc, similar or 
lighter oral frame and ventral arms. The dorsal arms show alternating light and dark bands and a series of light and dark spots along the distal edge of the dorsal arm plates.

\section{Other specimens}

SMNH-35614 15.5 mm dd, SMNH-123374 16.3 mm dd, SMNH-123375 $14.3 \mathrm{~mm}$ dd. Colour faded to light brown. Most of the granules rubbed off the discs, and status of the radial shields as naked/granule covered cannot be assessed, but they have an exposed area, devoid of scales. Eight oral papillae. Two to three dorsal arm plates on single joints (SMNH-123374), up to nine joints (SMNH-123375), up to 12 joints (SMNH-35614), variable between arms. Juveniles present in the bursae.

\section{Remarks}

The origin of this species through an ancient hybridization event between $O$. longicauda and $O$. zibrowii sp. nov. (or their ancestors) (Weber et al. 2019) is further supported by its high morphological variability. Multiple dorsal arm plates are typical of $O$. longicauda, and in some specimens of $O$. hybrida sp. nov.

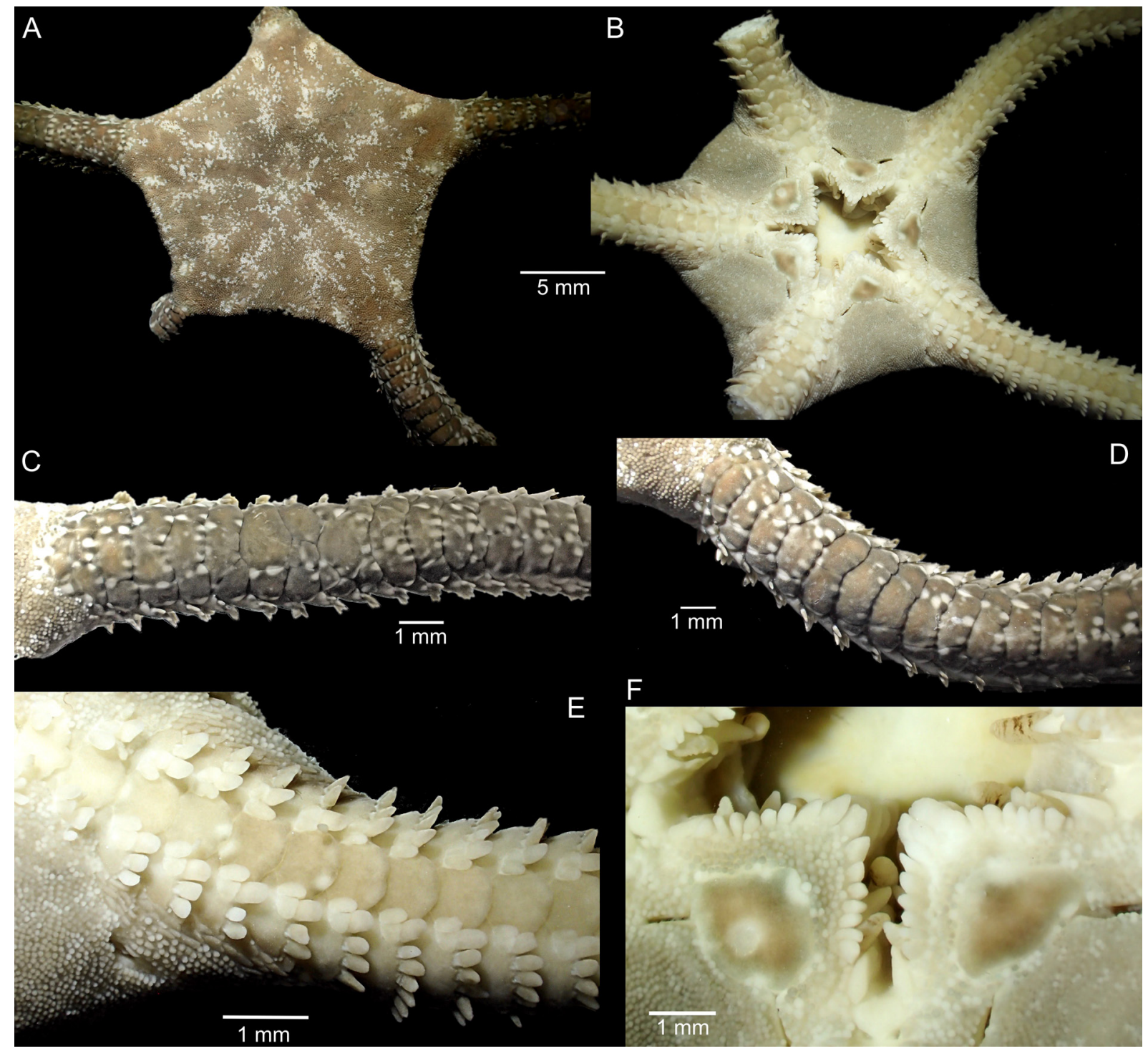

Fig. 9. Ophioderma hybrida sp. nov., holotype (SMNH-Type-9185), digital images. A. Dorsal aspect. B. Ventral aspect. C-D. Two dorsal arms, note the multiple dorsal plates. E. Ventral arm. F. Jaws. 


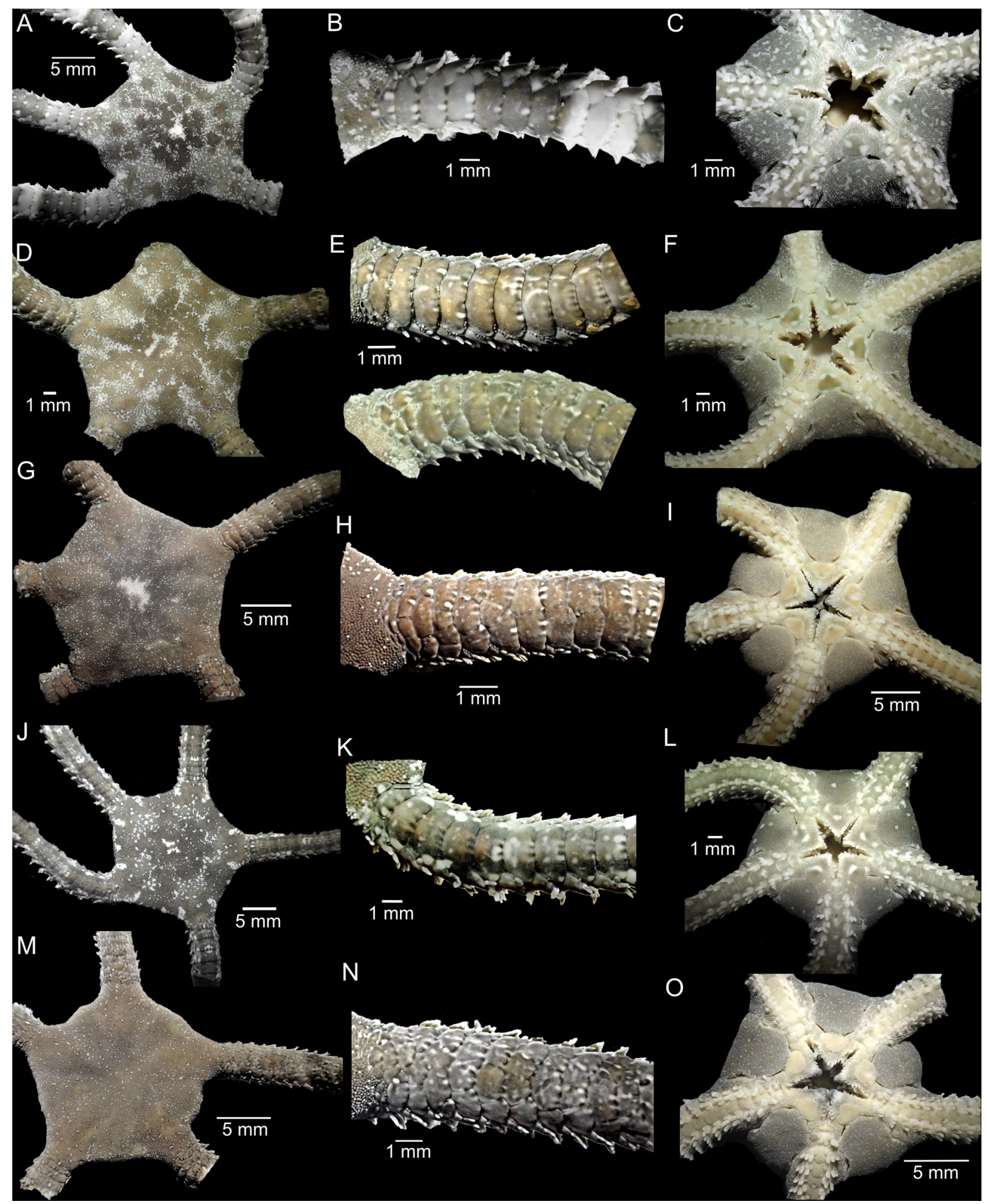

Fig. 10. Colour variation and numbers of dorsal arm plates (DAP) in Ophioderma hybrida sp. nov., digital images. Right column shows dorsal disc, middle column shows dorsal arm, left column shows ventral disc. A-F. Paratypes from Tunisia, Monastir (SMNH-Type-9187). A-C. MON17, single DAPs. D-F. MON16, one arm with 1-2 DAPs, other arm with $\geq 2$ DAPs. - G-O. Paratypes from Tunisia, Kelibia (SMNH-Type-9186). G-I. KEL5, $\geq 2$ DAPs. J-L. KEL10, single DAPs. M-O. KEL12, $\geq 2$ DAPs. For specimen data see Table 2 . 


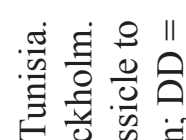

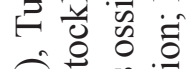
준,

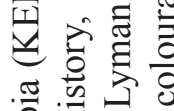
的诸

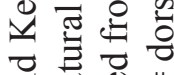

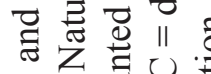

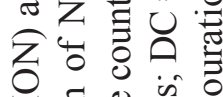

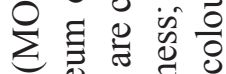

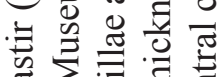

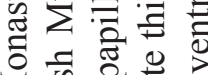

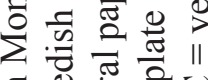

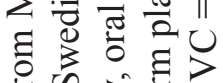

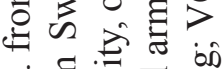

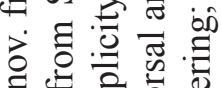

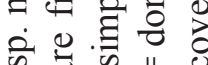

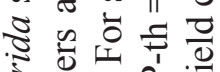

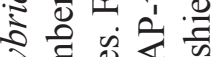
s. 告 政

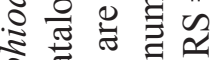

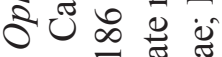
. $=\bar{a} \frac{\pi}{2}$

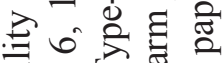
줍

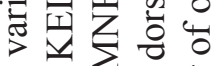

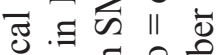
. 웜 글. 可 कृ के है के

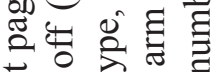
离 过 च छ

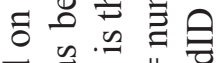

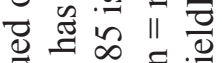
药 : 造焉焉

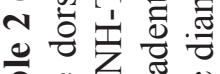

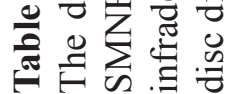
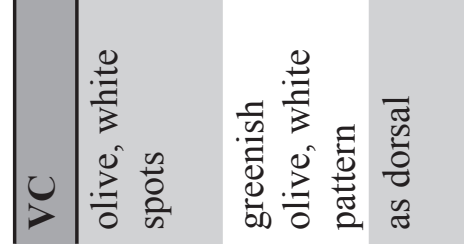

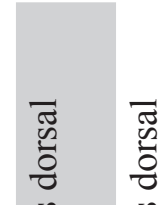

章

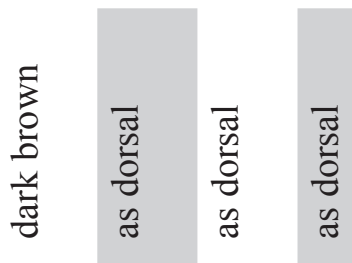

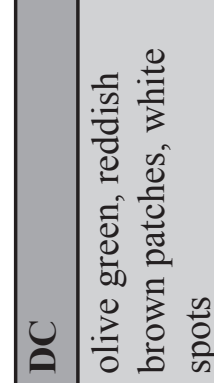

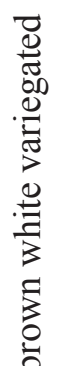

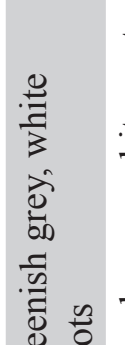

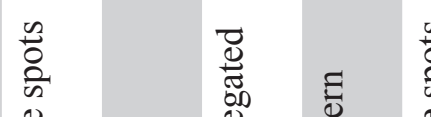

$=$

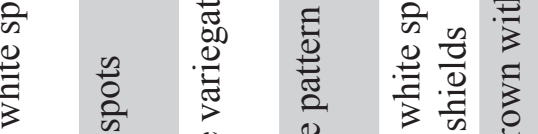

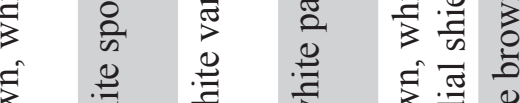

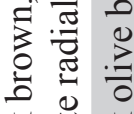

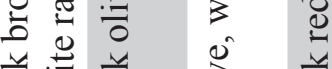

$\stackrel{2}{0}$

ही

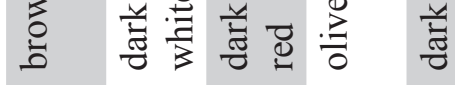

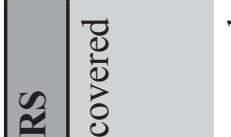

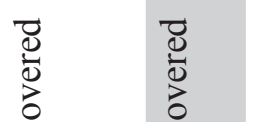

ฮิ่อ

章

齐

$\begin{array}{ll}\text { ¿ } & 0 \\ 0 & 0 \\ 0 & 0 \\ 0 & 0\end{array}$

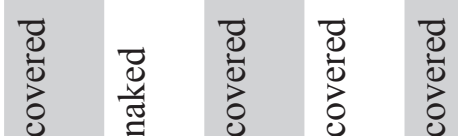

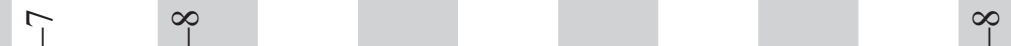

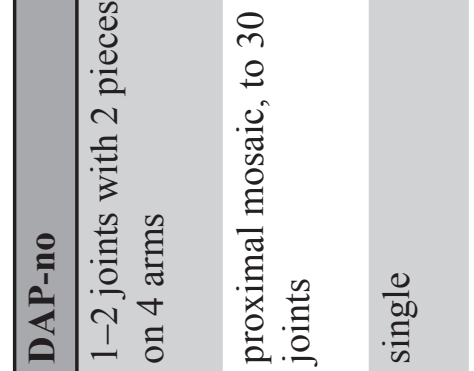

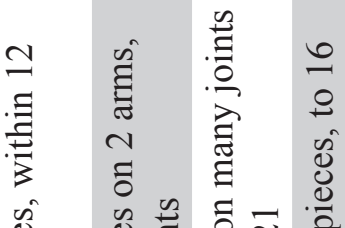

แึ

造

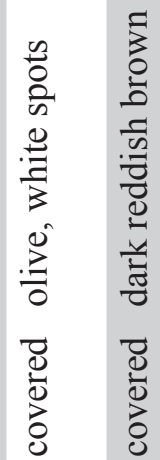

i

$\infty \quad \begin{array}{lll}1 & 0 \\ \infty & \infty & 0\end{array}$

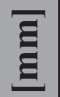

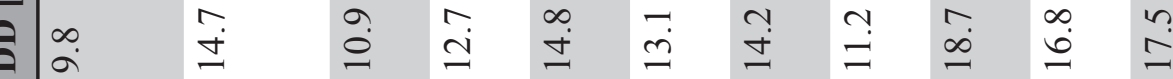

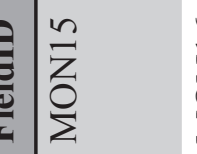

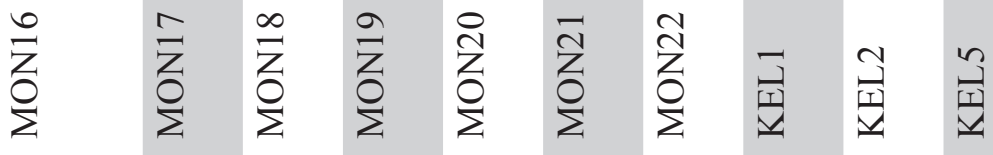

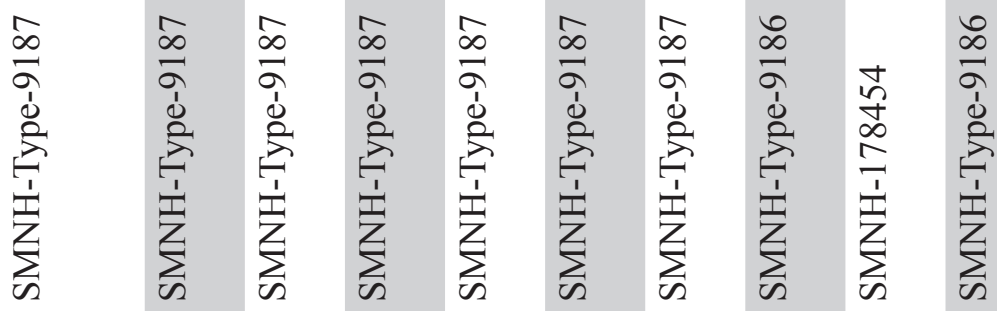




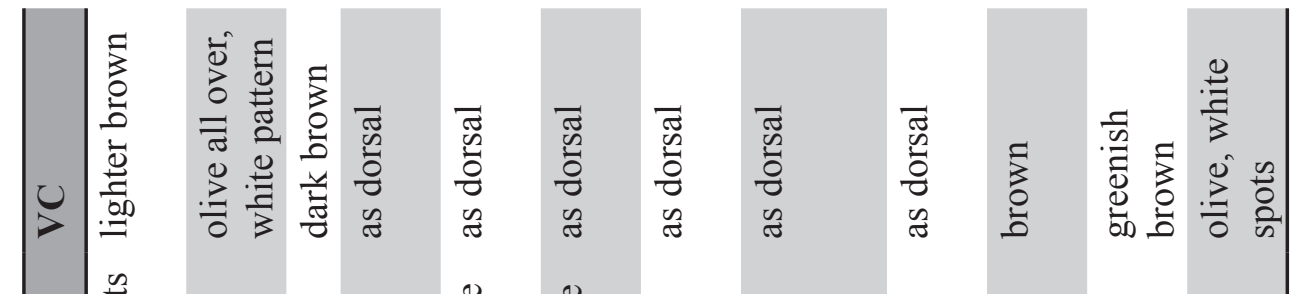

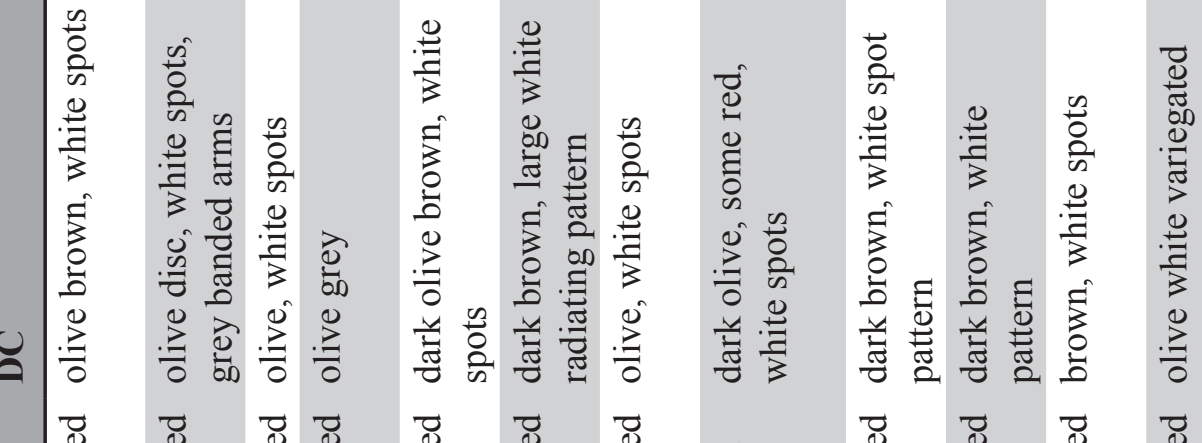

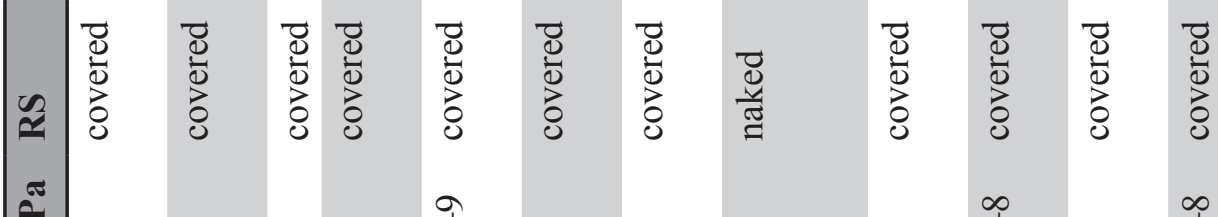

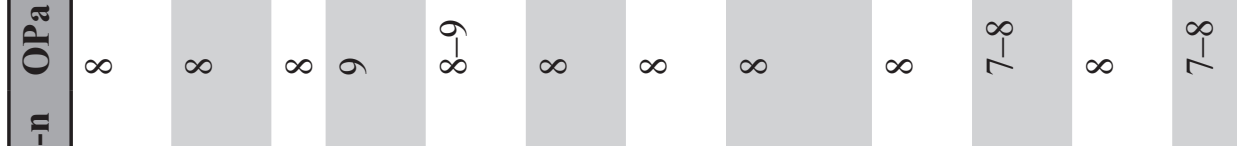

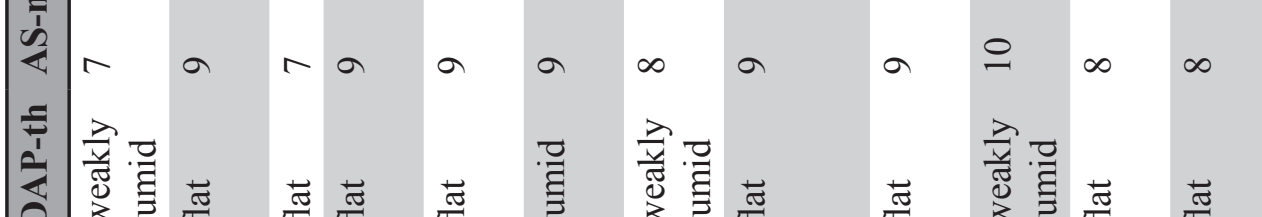

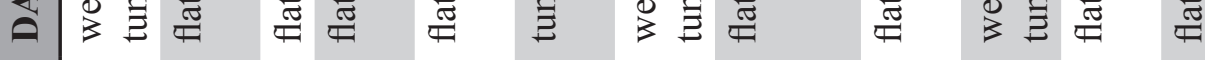

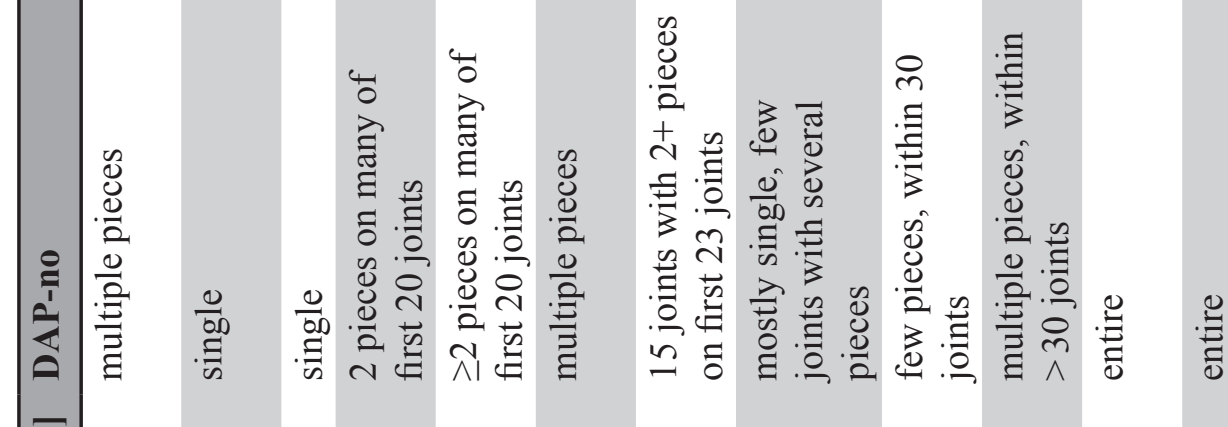

啇

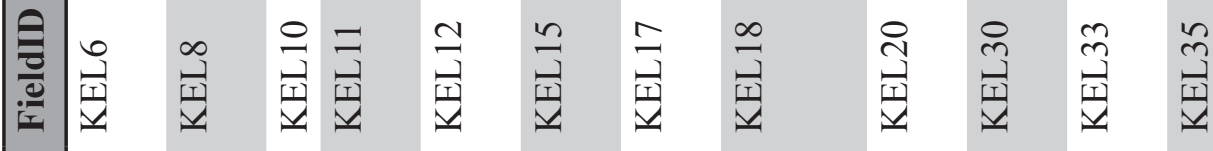

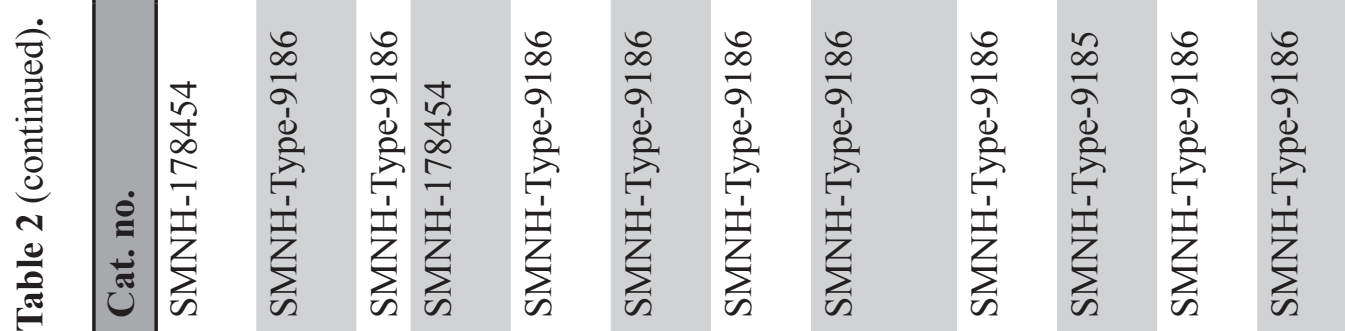


the most proximal joints bear several plates, forming a crowded mosaic pattern similar to O. longicauda. The usually granule covered radial shields are shared with all species except $O$. zibrowii sp. nov. (Table 1) and are probably evidence of $O$. longicauda (or its ancestor) being one of the ancestral species. The variation of arm spines and oral papillae overlap with both ancestral species and $O$. africana sp. nov., but $O$. guineense has a higher number of arm spines. Ophioderma hybrida sp. nov. shares the vivid colour pattern of the arms with $O$. zibrowii sp. nov. and $O$. guineense, whereas $O$. africana sp. nov. and O. longicauda are darker and the spots on the arms are less obvious in the former. So far, O. hybrida sp. nov. appears to be a smaller species with disc diameter under $20 \mathrm{~mm}$, but more material is needed to confirm this. We believe that the reproductive mode of $O$. hybrida sp. nov. is brooding given that brooding individuals have been collected in Tunisia (Stöhr et al. 2009) and the ones examined in this study are morphologically more similar to $O$. hybrida sp. nov. than to O. zibrowii sp. nov., because they have more dorsal arm plates per joint. Yet, we cannot confirm it, as the brooding specimens from Tunisia were too old for genetic analyses (1849 and 1924; PCR amplification failed). In addition, all other $O$. hybrida sp. nov. specimens have been collected outside the reproductive season so examination of their gonads was inconclusive in determining their reproductive strategy.

Ophioderma zibrowii sp. nov.

urn:1sid:zoobank.org:act:7FB245FD-C8DF-402A-A7B1-FA7D048AFB04

Figs 11-12; Table 1

\section{Diagnosis}

Usually naked radial shields. Seven arm spines. Eight oral papillae. Colour pattern greenish brown to dark green variegated on dorsal and ventral disc, arms banded, with light and dark spots along distal dorsal plate edges, oral frame and ventral arms lighter. Largest known size $21 \mathrm{~mm}$ dd. Brooder.

\section{Etymology}

The species is named after Helmut Zibrowius for his important contributions in collecting material for this study. The existence of brooding Ophioderma in the Mediterranean Sea might still be unknown without his effort.

\section{Material examined}

Holotype

MEDITERRANEAN SEA • + (brooding); southern Crete, Agios Pavlos; May 2012; A. Weber leg.; preserved in 95\% ethanol; SMNH-Type-9188.

\section{Paratypes}

MEDITERRANEAN SEA $1+$ (brooding); same data as for holotype; SMNH-Type-9189 7 specimens; Greece, Symi Island, near Rhodes, Agios Georgios; 10 Aug. 2005; R. Graille leg.; preserved in 95\% ethanol; SMNH-Type-9190 to 9196.

\section{Other material}

MEDITERRANEAN SEA 18 specimens (mitochondrial COI lineage L3, nuclear cluster C5); Greece, northwestern Crete, Elounda, Plaka Beach; 2 Jul. 2008; Emilie Aegea leg.; preserved in 95\% ethanol; SMNH-102712, 113690 to 13697,11370 to 113704,113709 to $113712 \cdot 21$ specimens (mitochondrial COI lineage L3, nuclear cluster C5); Greece, Rhodes, Kallithea Bay; 9 Sep. 2005; H. Zibrowius leg.; preserved in 95\% ethanol; SMNH-99657, 113982, 113985, 113987 to 113990,113992 to 114003 , 114005, 114006 • 41 specimens (mitochondrial COI lineage L3, nuclear cluster C5); Greece, Crete; May 2012; A. Weber leg.; preserved in 95\% ethanol; SMNH-147070 1 specimen $(\mathrm{dd}=15.4 \mathrm{~mm})$, dried dissociated ossicles and ossicles on two SEM stubs; same data as for preceding; SMNH-178455. 


\section{Description}

Holotype (Fig. 11)

Disc diameter $14.3 \mathrm{~mm}$, one intact arm, all others removed for molecular analysis. Dorsal disc with dense cover of granules, radial shields naked, widely separated, visible part oval (Fig. 11A). Granules and scales crowd onto basal arms. Dorsal arm plates single on all joints, flat, overlapping, broadly fanshaped, twice as wide as long, with straight edges, wider distally than proximally (Fig. 1D). Up to seven conical, slightly pointed arm spines, about equal in length, half as long as arm joint, ventralmost spine thicker than others and blunt (Fig. 7C). Ventral disc covered by granules similar to dorsal disc. Adoral shields and oral plates covered by granules, oral shields naked (Fig. 11B). Seven to eight oral papillae, Lyman's ossicle elongated, pointing into mouth slit, adoral shield spines two, block shaped, other papillae smaller, conical (Fig. 11E). Tooth papillae larger, conical, two in line with oral papillae. Oral shields

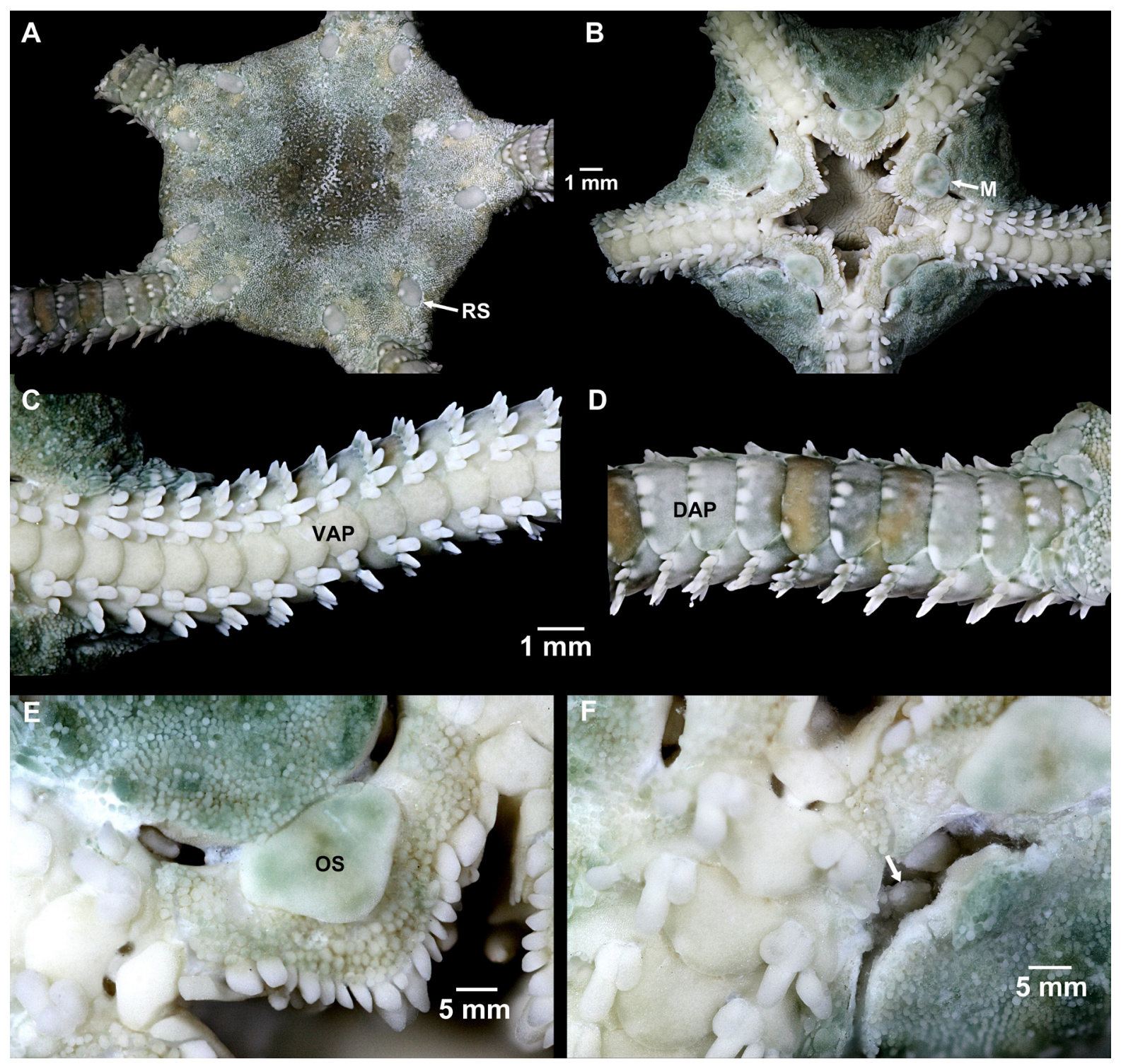

Fig. 11. Ophioderma zibrowii sp. nov., holotype (SMNH-Type-9188), digital images. A. Dorsal aspect, note the naked radial shields. B. Ventral aspect. C. Ventral arm. D. Dorsal arm, note the entire plates. E. Jaw. F. Brooded juveniles in interradius (arrow). Abbreviations: DAP $=$ dorsal arm plate; $\mathrm{M}=$ madreporite; $\mathrm{OS}=$ oral shield; $\mathrm{RS}=$ radial shield; $\mathrm{VAP}=$ ventral arm plate. 
triangular, twice as wide as long, straight distal edge, obtuse rounded proximal angle. Madreporite as wide as long. Adoral shield long, narrow, extending around the lateral edge of the oral shield, separating it from the arm. Adoral shields covered with granules, similar to disc granules. Proximal genital slits parallel to and as long as first and second joints. Distal genital slit parallel to and as long as fourth joint, at distance from disc edge. Bursae filled with brooded juveniles (Fig. 11F).

Dorsal disc slightly variegated dark brown-green with grey, dorsal arms greyish green with brown bands, each light and dark band about three joints wide, a series of larger white and smaller black spots along the distal edge of each dorsal arm plate (Fig. 11A, D). Ventral disc as dark as dorsal, oral frame and ventral arms lighter grey-green (Fig. 11B). Arm spines grey-green with white tips, except ventralmost spine, which is white (Fig. 11C-D). Oral papillae and tentacle scales white (Fig. 11C, E).

\section{Paratypes}

Disc diameter 9.7-13.5 $\mathrm{mm}$. All have up to seven arm spines. Most paratypes have a green colour pattern similar to the holotype, one specimen is olive-brown. One paratype with granule-covered radial shields, all others naked. Oral papillae eight, in two specimens nine, but variable between jaws in an individual. Two specimens with two dorsal arm plates on 2-3 proximal joints on 1-3 arms. One specimen with 2-3 dorsal arm plates on proximal joints on three arms, on seven joints on one of those arms. One specimen has a parasitic snail (Ersilia Monterosato, 1872 sp.) on one arm. All paratypes lack part of an arm, which was used for molecular analysis.

\section{Non-paratypes (SMNH-147070)}

Disc diameter 8.4-20.5 mm. Specimens smaller than $10 \mathrm{~mm}$ dd had six arm spines, all others seven. Most specimens have a green colour pattern similar to the holotype, several were dark olive with numerous white granules scattered across the disc. Out of the 42 specimens, a single one had granule-covered radial shields, all others with naked radial shields. Most of the specimens above $10 \mathrm{~mm}$ dd had at least two proximal arm joints on at least one arm with two dorsal arm plates, up to seven joints and several arms with double plates in one animal. The plates were usually of equal size or there was a hairline crack along the midline of the plate. Rarely, a third dorsal arm plate was present on one or two joints. Oral papillae eight, rarely nine, but variable between jaws in an individual and not correlated to size. These specimens were used for thermotolerance and regeneration experiments. These specimens were kept in an aquarium for a year where experiments of thermotolerance and regeneration were conducted. Therefore, most arms show signs of regeneration. One specimen had bright white distal arms but no sign of healed breaks. Maximum size recorded for O. zibrowii sp. nov. was $21 \mathrm{~mm}$ dd (Weber et al. 2014).

Skeletal elements (Fig. 12)

Non-type specimen of $15.4 \mathrm{~mm}$ dd (SMNH-178455), completely dissociated. Radial shields elongated isosceles triangular, external surface with embossed oval of more finely meshed stereom in center of domed and thickened proximal half (only visible part in intact skeleton), row of eight pores curves around proximal dome (Fig. 12A, C). On inner side of radial shield, a large pore on distal half and a round patch with denser stereom, two low distal bulbs separated by a furrow (Fig. 12B). Dental plate consists of several pieces, sockets not penetrating the plate, bordered by low rim, tooth papillae sockets smaller, round, tooth sockets wide, oval (Fig. 12D). Adradial genital plate blade-like flat with bulbous distal end and large pore, distal pit with knob on one side, three ridges on other side (Fig. 12E-F). Abradial genital plate much smaller and scale-like flat, distally wider than proximally (Fig. 12G). Oral plates longer than high, middle part markedly lower than ends, abradial muscle fossa rounded triangular, not reaching upper edge (Fig. 12H). On adradial oral plate proximoventral part four oral papilla sockets and pores, at proximoventral edge four granule sockets and pores (Fig. 12I). Vertebrae typically zygospondylus, with large dorsal and small ventral muscle flanges, no growth rings obvious (Fig. 12J-K). Lateral arm plates compact, weakly curved around the arm, strongly convex distally, concave proximally, with ventral 
excavation for tube foot opening (Fig. 12L-M). Two spurs at proximal external edge and counterparts on internal distal edge of lateral arm plates. Internal lateral arm plate with vertical row of three pores just below the plate centre, distal to curved vertical ridge, fourth pore in tentacle opening edge, small ventral knob, protruding beyond plate edge. Spine articulations inset in the distal plate edge with one thickened lobe, separating muscle and nerve opening.

\section{Remarks}

The species determination rests mainly on the genetic analyses. We chose the predominant genetic group (C5) to describe a new species, but due to its short reproduction period (May-June, Weber et al. 2014)

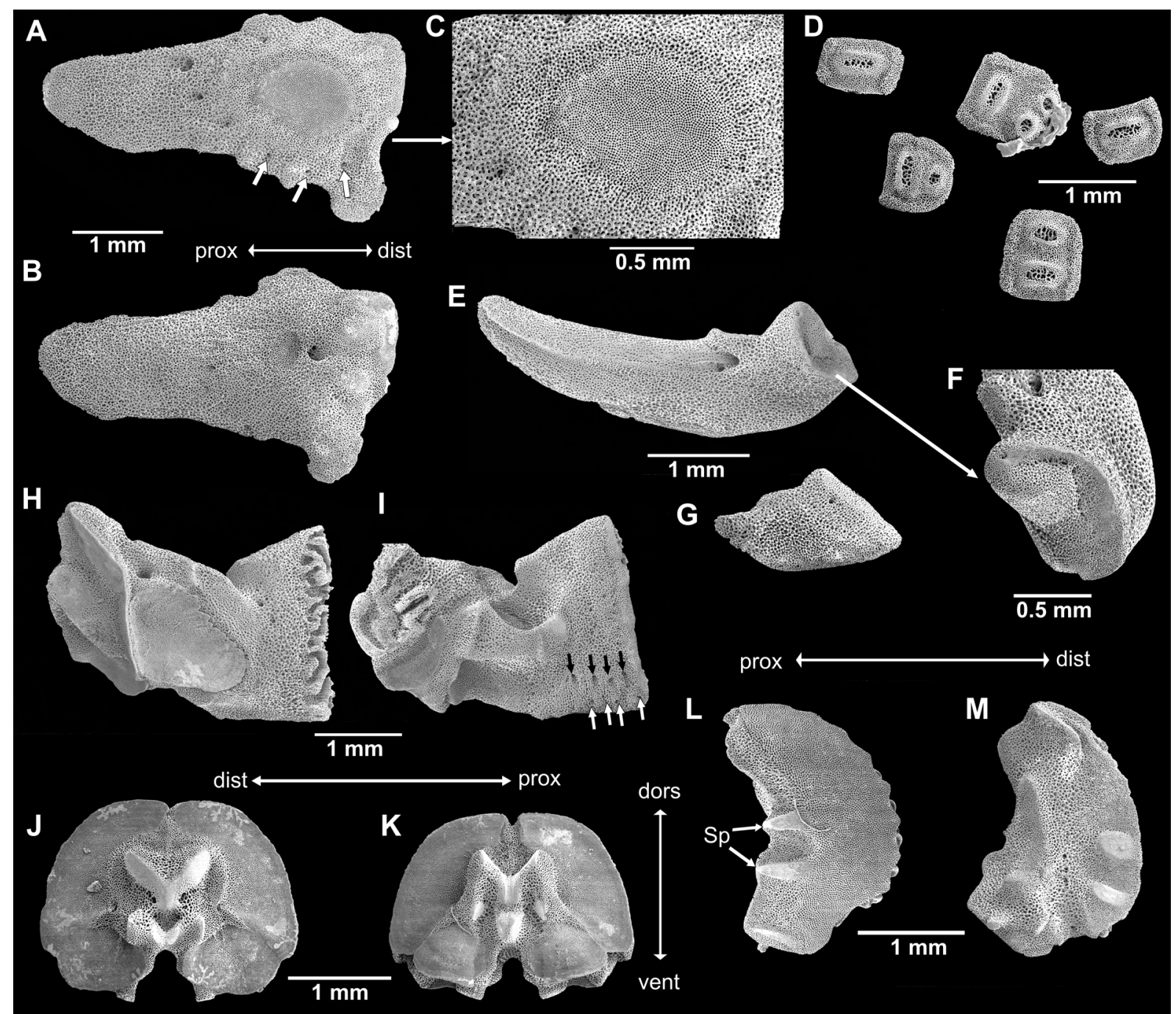

Fig. 12. SEM images of skeletal elements of Ophioderma zibrowii sp. nov., from non-type specimen of $15.4 \mathrm{~mm}$ disc diameter (SMNH-178455), Crete, Greece. A. Radial shield, external aspect, white arrows point to larger peripheral pores. B. Radial shield, internal aspect. C. Scale-free part magnified from Fig. 12A, note the absence of pores on the denser area (naked in intact animal, see Fig. 11A). D. Dental plate fragments. E. Adradial genital plate, lateral aspect. F. Distal end of Fig. 12E. G. Abradial genital plate. H. Oral plate, abradial face. I. Oral plate, adradial face, black arrows point to oral papillae sockets and pores. J. Arm vertebra, proximal face. K. Arm vertebra, distal face. L. Lateral arm plate, external face. M. Lateral arm plate, internal face. Abbreviations: dist $=$ distal; dors $=$ dorsal; prox $=$ proximal; $\mathrm{Sp}$ $=$ spurs; vent $=$ ventral . 
most specimens of this cluster happen to have been collected outside the brooding time. Since brooding is one of the key characters of this species, we felt that the holotype should be a brooding female. It is not ideal that the chosen animal has only a single intact arm remaining, but in a pentaradially symmetric animal one arm is sufficient and representative of the others.

Morphological differentiation from $O$. longicauda rests on the usually naked radial shields and the single, flat arm plates. Also, O. zibrowii sp. nov. usually lacks red pigments which are common in O. longicauda, whereas green pigments are common in O. zibrowii sp. nov. but absent in O. longicauda. In addition, $O$. zibrowii sp. nov. commonly has a series of white and black spots along the distal edge of the dorsal arm plates, which are shared with $O$. hybrida sp. nov. and O. guineense. The radial shields differ microscopically from those of $O$. longicauda in the clear demarcation of an embossed part with finer meshed stereom, representing the naked visible part of the radial shields in the intact animal. The major part of the radial shield is overlapped and covered by disc scales, obscuring its true shape. Possibly, the more elongated oral plates and higher lateral arm plates in $O$. zibrowii sp. nov. distinguish the species, but these small differences need to be studied with morphometric methods and larger samples.

Brooding females have been collected from Cyprus and Lebanon, but they belong to another genetic cluster (C6). Morphologically they cannot be distinguished at this time and we consider them to be allopatric populations within the same species. They are excluded from the concept of the new species $O$. zibrowii sp. nov., as new evidence may in the future lead to them being recognized as a different species.

\section{Discussion}

Previously, 28 species of Ophioderma were recognized (Stöhr et al. 2019). Now there are 32 species, after adding the resurrected $O$. guineense and the three herein newly described species. Among these, two species are known to brood their young, O. wahlbergii Müller \& Troschel, 1842 as first documented by Landschoff \& Griffiths (2015), and $O$. zibrowii sp. nov. described herein. In addition, O. hybrida sp. nov. is most likely a brooder (Weber et al. 2019). Compared to O. wahlbergii, O. zibrowii sp. nov. and $O$. hybrida sp. nov. are smaller, and $O$. zibrowii sp. nov. broods a larger number of young for a shorter time (Stöhr et al. 2009), suggesting that the brooding habit in the new species may have evolved more recently.

Geographical and ecological data, known as valuable information in integrative taxonomy, help to determine species of the O. longicauda complex and shed light on their origins. In the northern Mediterranean, west of Greece, only $O$. longicauda occurs today. Among the eastern populations, $O$. zibrowii sp. nov. can be distinguished from $O$. longicauda by a smaller maximum size, which however means that only specimens above $21 \mathrm{~mm}$ dd can safely be assigned to O. longicauda. Other characters, such as the radial shields, which are usually naked in O. zibrowii sp. nov. and most often covered by granules in $O$. longicauda, and the multiple arm plates in $O$. longicauda are more stable but not true for all specimens (e.g., small $O$. longicauda have single arm plates and multiple plates occur with low frequency in $O$. zibrowii sp. nov.). Differences in colour pattern, uniformly dark brown with red components in $O$. longicauda, usually variegated without red but with green in $O$. zibrowii sp. nov., and with spotted arm plates in $O$. zibrowii sp. nov. and $O$. hybrida sp. nov., seem to be consistent. Finally, $O$. zibrowii sp. nov. and $O$. hybrida sp. nov. have been found at shallower depths $(\sim 1 \mathrm{~m})$ compared to O. longicauda (>5-10 m) (Weber et al. 2013, 2014, 2019). In the eastern Tropical Atlantic off West Africa, no brooders have been found yet and O. longicauda is absent. The main differences between $O$. guineense and $O$. longicauda are single vs multiple dorsal arm plates, and fewer arm spines in the latter, as well as the light ventral disc and spotted dorsal arm plates in O. guineense. The most reliable character to identify Ophioderma africana sp. nov. seems to be the dark ventral disc, and it differs from the similarly coloured $O$. longicauda by its smaller number of arm plates. 
The most difficult to recognize species is $O$. hybrida sp. nov. because its morphology is more variable than in the other species, and each individual shares traits with both ancestral species, but in variable proportions. Moreover, it has so far only been found in Tunisian waters, where also O. longicauda occurs. However, most individuals of $O$. hybrida sp. nov. can be identified by the white spots along the distal edge of each dorsal arm plate, in combination with a high frequency of multiple arm plates, although we cannot completely rule out that $O$. zibrowii sp. nov. may occur in sympatry. Ophioderma hybrida sp. nov. does most likely not hybridize with $O$. zibrowii sp. nov. and $O$. longicauda, which are the extant species that are closest to its ancestors. The main argument is that genetic clustering (a type of discriminant analysis), based on multilocus DNA genotypes, recovered six clusters and assigned all the individuals found in Tunisia either to cluster $\mathrm{C} 3$ (O. longicauda) or to $\mathrm{C} 4$ (O. hybrida sp. nov.), with no ambiguity (100\% probability), which strongly supports that hybridization is presently absent or extremely marginal (Weber et al. 2019). There are also some morphological and biogeographic arguments ruling out that $O$. hybrida sp. nov. specimens may be first generation (F1) hybrids of $O$. longicauda $\times$ $O$. zibrowii sp. nov. crosses. Although numerous specimens were analysed with morphology and/or genetics, we observed no individuals in the geographic range of $O$. zibrowii sp. nov. and $O$. hybrida sp. nov. that could be considered F1. This F1 hypothesis is further ruled out by the great morphological diversity observed among $O$. hybrida sp. nov. individuals; indeed, F1 populations are expected to be morphologically and genetically homogeneous, compared to F2 or backcrossed ones. We cannot rule out that very occasional hybridizations are possible between $O$. hybrida sp. nov. and O. longicauda in Tunisia, but local genetic data do not support it, and reproduction seasons (although not established in Tunisia) seem to be incompatible (O. longicauda in France reproduces in summer (Fenaux 1972), while O. zibrowii sp. nov. in Greece reproduces in spring (Weber et al. 2014)).

A previously not recognized character of taxonomic value is the shape of the radial shields with their more or less embossed scale-free part in $O$. zibrowii sp. nov., compared to the merely domed radial shields in the other species. However, their examination requires destructive preparation and SEM, and it is thus not feasible for the identification of large numbers of specimens or under field conditions. In addition, the shape of the radial shields varies between and within individuals, and without statistic analysis of a larger sample, the phylogenetic (and thus taxonomic) signal in the radial shields cannot be fully assessed. The oral plates of $O$. zibrowii sp. nov. and $O$. guineense seem to be lower than those of $O$. longicauda and $O$. africana sp. nov., which appear slightly more compact in shape, but variation within and between individuals is unknown, and oral plates have not been studied with modern methods. In addition, molecular data do not support a monophyletic origin of $O$. zibrowii sp. nov. and $O$. guineense (Weber et al. 2019), and O.guineense is the oldest species in the complex (Fig. 1).

The colour patterns observed here are all based on animals preserved in ethanol. Unfortunately, their live colours are incompletely known. Some pigments appear to dissolve more readily in ethanol than others, and we have observed that the fluid in which our O. longicauda and O. africana sp. nov. are preserved has a reddish tone, whereas the fluid with all other species is colourless. Interestingly, the West African O. guineense shares the spotted disc and arms with the Levantine species, but it is the only one with a light coloured ventral disc.

The differentiation of species in the O. longicauda complex is a striking example of cryptic speciation in brittle stars. Although molecular data suggest that up to six species may be involved, only five can be differentiated morphologically so far and with limitations regarding juvenile specimens and overlapping plasticity. Occasional hybridization among the brooding lineages and between them and the broadcasters cannot be ruled out, and incomplete lineage sorting has been observed (Weber et al. 2019).

Species geographic distributions, resulting from the joint action of dispersal processes and local selective pressures, can help to determine the ecological niches of the species. Dispersal is predicted to be limited 
in brooders with respect to broadcasters, hence geographic ranges of the latter are expected to be smaller; as observed in the Mediterranean basin, where the broadcaster $O$. longicauda $(\mathrm{C} 3)$ is present in every location sampled, contrary to the brooder $O$. zibrowii sp. nov. (C5-C6), which is restricted to some of the Levantine locations. As for selective factors, Boissin et al. (2011) found that the presence of brooders was associated with the presence of oligotrophic waters and suggested that the evolution of brooding in the species complex was linked to adaptation to oligotrophic waters. In addition, when in sympatry (in Greece and Lebanon), brooders were more abundant than broadcasters in the shallowest areas (and conversely), which suggests that they had differentiated, yet overlapping, ecological niches (Weber et al. 2014, 2019). Different ecological optimal niches associated with interspecific competition probably shape the patterns of co-occurrence of brooders and broadcasters in sympatric areas.

Reproduction seasons do not overlap between northern Mediterranean O. longicauda and O. zibrowii sp. nov. (Weber et al. 2014), which begs the question how they hybridized into $O$. hybrida sp. nov., but possibly, reproduction times may differ in the southern Mediterranean or may have changed since this ancient hybridization event happened and led to speciation as a result of reinforcement. Indeed, it has been shown that genes coding for sperm motility were evolving faster in $O$. zibrowii sp. nov., which may have evolved to prevent further hybridization with O. longicauda (Weber et al. 2017). At present, the full geographic ranges of the newly recognized species are unknown. It is possible that some of them are locally restricted on a small scale, but more data are needed.

\section{Acknowledgements}

A large part of the material used in the long-term study of the O. longicauda species complex was collected and donated by H. Zibrowius (University of Marseille), who also collected the very first brooding female, donated it to S. Stöhr and informed Anne Chenuil on the interest of studying this taxon. We are greatly indebted to him. We thank A. Schmidt-Rhaesa (Zoological Museum, Hamburg) for the loan of syntypes of $O$. guineense and photos of the remaining syntypes. We thank T. Schiøtte (Zoological Museum, Copenhagen) for the loan of Senegal material, and Jonas Ekström for searching the collections of the Zoological Museum Lund for type material of $O$. longicanda.

\section{References}

Boissin E., Stöhr S. \& Chenuil A. 2011. Did vicariance and adaptation drive cryptic speciation and evolution of brooding in Ophioderma longicauda (Echinodermata: Ophiuroidea), a common AtlantoMediterranean ophiuroid? Molecular Ecology 22: 4737-4755.

https://doi.org/10.1111/j.1365-294X.2011.05309.x

Boissin E., Hoareau T.B., Paulay G. \& Bruggemann J.H. 2017. DNA barcoding of reef brittle stars (Ophiuroidea, Echinodermata) from the southwestern Indian Ocean evolutionary hot spot of biodiversity. Ecology and Evolution 7: 11197-11203. https://doi.org/10.1002/ece3.3554

Bruzelius N. 1805. Dissertatio sistens species cognitas asteriarum, quamr. sub praesidio D.M. and J. Retzii, pro laurea modeste exhibet Nicolaus Bruzelius. Berlingianis, Lund.

Chenuil A., Cahill A.E., Délémontey N., Du Salliant du Luc E. \& Fanton H. 2019. Problems and questions posed by cryptic species. A framework to guide future studies. In: Casetta E., Marques da Silva J. \& Vechhi D. (eds) From Assessing to Conserving Biodiversity: Conceptual and Practical Challenges. History, Philosophy and Theory of the Life Sciences 24: 77-106. Springer International Publishing, Cham. https://doi.org/10.1007/978-3-030-10991-2_4

Clark A.M. 1976. Ophiura Lamarck, 1801 and Ophioderma Müller \& Troschel, 1840: revised proposals for stabilisation. Z.N.(S.) 1772. Bulletin of Zoological Nomenclature 32: 265-267. 
STÖHR S. et al., Ophioderma longicauda complex resolved

Fenaux L. 1969. Le développement larvaire chez Ophioderma longicauda (Retzius). Cahier de Biologie marine 10: 59-62.

Fenaux L. 1972. Evolution saisonnière des gonades chez l'Ophiure Ophioderma longicauda (Retzius), Ophiuroidea. Internationale Revue der gesamten Hydrobiologie und Hydrographie 27: 257-262. https://doi.org/10.1002/iroh.19720570205

Greeff R. 1882. Echinodermen beobachtet auf einer Reise nach der Guinea-Insel São-Thomé. Zoologischer Anzeiger 107: 156-159.

Hendler G. 2018. Armed to the teeth: a new paradigm for the buccal skeleton of brittle stars (Echinodermata: Ophiuroidea). Contributions in Science 526: 189-311.

Hendler G., Miller J.E., Pawson D.L. \& Kier P.M. 1995. Sea stars, sea urchins, and allies. Echinoderms of Florida and the Caribbean. Smithsonian Institution Press, Washington and London.

Koehler R. 1914. Echinoderma I. Asteroidea, Ophiuroidea et Echinoidea. In: Michaelsen E. (ed.) Beiträge zur Kenntnis der Meeresfauna Westafrikas Vol. 1: 127-303. L. Friederichsen \& Co., Hamburg. https://doi.org/10.5962/bhl.title.7400

Landschoff J. \& Griffiths C.L. 2015. Brooding behavior in the shallow-water brittle star Ophioderma wahlbergii. Invertebrate Biology 134: 168-179. https://doi.org/10.1111/ivb.12081

Madsen F.J. 1970. West African ophiuroids. Atlantidae Report 11: 151-243.

Melville R.V. 1980. Opinion 1152. Ophiura Lamarck, 1801 and Ophioderma Müller \& Troschel, 1840 (Ophiuroidea): ruling on application of these names. Bulletin of Zoological Nomenclature 37 (2): 78-80.

Müller J. \& Troschel F.H. 1840. Über die Gattungen der Ophiuren. Archiv für Naturgeschichte, Berlin 6: $326-330$.

Stöhr S., Boissin E. \& Chenuil A. 2009. Potential cryptic speciation in Mediterranean populations of Ophioderma (Echinodermata: Ophiuroidea). Zootaxa 2071: 1-20.

https://doi.org/10.11646/zootaxa.2071.1.1

Stöhr S., O’Hara T.D. \& Thuy B. 2019. World Ophiuroidea Database. World Register of Marine Species. Available from http://www.marinespecies.org/ophiuroidea [accessed 4 Sep. 2019].

https://doi.org/10.14284/358

Tortonese E. 1983. Remarks on the morphology and taxonomy of Ophioderma longicaudum (Retz.) from the Mediterranean. Atti della Societa Italiana di Scienze naturali e del Museo civico di Storia naturale in Milano 124: 21-28.

Weber A.A.-T., Abi-Rached L., Galtier N., Bernard A., Montoya-Burgos J.I. \& Chenuil A. 2017. Positive selection on sperm ion channels in a brooding brittle star: consequence of life-history traits evolution. Molecular Ecology 26: 3744-3759. https://doi.org/10.1111/mec.14024

Weber A.A.-T., Mérigot B., Valière S. \& Chenuil A. 2015. Influence of the larval phase on connectivity: strong differences in the genetic structure of brooders and broadcasters in the Ophioderma longicauda species complex. Molecular Ecology 24: 6080-6094. https://doi.org/10.1111/mec.13456

Weber A.A.-T., Dupont S. \& Chenuil A. 2013. Thermotolerance and regeneration in the brittle star species complex Ophioderma longicauda: a preliminary study comparing lineages and Mediterranean basins. Comptes Rendus Biologies 336: 572-581. https://doi.org/10.1016/j.crvi.2013.10.004

Weber A.A.-T., Stöhr S. \& Chenuil A. 2014. Genetic data, reproduction season and reproductive strategy data support the existence of biological species in Ophioderma longicauda. Comptes Rendus Biologies 337: 553-560. https://doi.org/10.1016/j.crvi.2014.07.007 
Weber A.A.-T., Stöhr S. \& Chenuil A. 2019. Species delimitation in the presence of strong incomplete lineage sorting and hybridization: lessons from Ophioderma (Ophiuroidea: Echinodermata). Molecular Phylogenetics and Evolution 131: 138-148. https://doi.org/10.1016/j.ympev.2018.11.014

Ziesenhenne F.C. 1955. A review of the genus Ophioderma M. \& T. In: Allan Hancock Foundation staff (eds) Essays in the Natural Sciences in Honour of Captain Alan Hancock: 185-201. Los Angeles University of Southern California Press, Los Angeles. https://doi.org/10.5962/bhl.title.6088

Manuscript received: 4 September 2019

Manuscript accepted: 4 November 2019

Published on: 4 February 2020

Topic editor: Rudy C.A.M. Jocqué

Desk editor: Radka Rosenbaumová

Printed versions of all papers are also deposited in the libraries of the institutes that are members of the EJT consortium: Muséum national d'histoire naturelle, Paris, France; Meise Botanic Garden, Belgium; Royal Museum for Central Africa, Tervuren, Belgium; Royal Belgian Institute of Natural Sciences, Brussels, Belgium; Natural History Museum of Denmark, Copenhagen, Denmark; Naturalis Biodiversity Center, Leiden, the Netherlands; Museo Nacional de Ciencias Naturales-CSIC, Madrid, Spain; Real Jardín Botánico de Madrid CSIC, Spain; Zoological Research Museum Alexander Koenig, Bonn, Germany; National Museum, Prague, Czech Republic. 


\section{Electronic supplementary material}

Supplementary file 1

Type material of Ophioderma species. $\mathrm{HT}=$ holotype; $\mathrm{LT}=$ lectotype; $\mathrm{NT}=$ neotype; $\mathrm{PL}=$ paralectotype; $\mathrm{PT}=$ paratype; $\mathrm{SMNH}=$ Swedish Museum of Natural History (invertebrate collections); ZMH = Zoological Museum Hamburg. 